\title{
Seismic Damage Detection of Moment Resisting Frame Structures Using Time-Frequency Features
}

\author{
Dongwang Tao $\mathbb{D}^{\text {, }}$, Qiang Ma $(\mathbb{D}$, and Shanyou Li \\ Key Laboratory of Earthquake Engineering and Engineering Vibration, Institute of Engineering Mechanics, \\ China Earthquake Administration, Harbin 150080, China \\ Correspondence should be addressed to Dongwang Tao; taodongwang@iem.ac.cn
}

Received 25 May 2018; Revised 23 July 2018; Accepted 30 July 2018; Published 23 September 2018

Academic Editor: Luca Z. Fragonara

Copyright $(92018$ Dongwang Tao et al. This is an open access article distributed under the Creative Commons Attribution License, which permits unrestricted use, distribution, and reproduction in any medium, provided the original work is properly cited.

To detect seismic damage of moment resisting frame (MRF) structures, a data-driven method using the fractal dimension (FD) of time-frequency feature (TFF) of structural seismic dynamic responses at measured stories is extended and refined. The TFF is defined as the real part of Gabor wavelet transform of translational interstory displacement, and FD is used to give a quantitative value to describe the calculated TFF. Static condensation method is first used to reduce the degrees-of-freedom (DOFs) of MRF and to express the rotational displacements using translational displacements. For linear MRF, the FDs of TFFs at all stories are the same using the definition of TFF and modal superposition principle. For damaged MRF with plastic hinges at the ends of beams and columns, the force analogy method is implemented to establish transformation matrix from plastic hinge rotations to translational interstory inelastic displacements. Due to the sparseness of the transformation matrix, plastic hinges only generate interstory inelastic displacements, which are low-frequency contents, in the vicinity of plastic hinges. Correspondingly, the FDs of TFFs of interstory displacements with inelastic component are different from the FDs of TFFs of the interstory displacements that do not contain inelastic component. A numerical simulation on a 16-story MRF was conducted. The simulation included 10 cases such as no damage or linear structure, plastic hinges in single-story beams, plastic hinges in single-story columns, plastic hinges in single-story beams and columns, and plastic hinges in multiple story beams and columns. The robustness to measurement noise was also investigated. The seismic damage detection results demonstrated that the proposed method was capable of locating the stories where the plastic hinges occurred.

\section{Introduction}

After big earthquakes occur, the national and local governments and owners, in order to take actions of postearthquake emergency rescue and reconstruction, need to know the safety and applicability of building structures damaged by strong ground motions [1]. Traditional postearthquake evaluation method for building structures is to arrange a large number of structural experts to inspect tens of thousands of damaged structures, check the damage of beams, columns, walls, stories, and roofs, and mark the damaged structures as intact, slightly damaged, medium damage, severe damage, and collapse categories [2]. This procedure is time consuming and laborious, and it is difficult to assess the internal damage which cannot be seen by eyes and the assessment is not objective. For example, after the Kobe earthquake in 1995, postearthquake investigation of 46,000 damaged structures in one disaster-stricken area took 6,000 structural experts spending up to three weeks to complete just a preliminary assessment of the damage structures [3]. This seriously delayed the emergency rescue and reconstruction after the earthquake. In addition, the damaged structures may collapse in the subsequent aftershocks and pose a life threat to the investigating structural experts. On the other hand, vibrationbased structural health monitoring (SHM) provides a new rapid and effective approach for structural health condition determination and seismic damage assessment [4-10]. SHM deploys sensors to acquire the dynamic responses of the prototype structures under real service environments and external loads, extracts damage-sensitive features hidden in the measurements, and provides safety information of the monitored structures in real time or near real time. SHM does 
not induce additional damage or negative effect to the structural and nonstructural components and does not affect the normal operation and service of the monitored structure. The assessment of structural damage by SHM is automatic, rapid, and effortless. Hence, SHM provides promising means for assessing the safety condition of structures prone to earthquakes, especially heritage structures such as towers and churches [11-14].

Damage detection is the core part of SHM, and the first important information needed for damage assessment and seismic retrofit for structures shaken by strong ground motions is to determine whether the structures is damaged and where the locations of damage are. Structural seismic damage is divided into three levels as component-level damage, storylevel damage and structure-level damage. Due to the complexity and huge degrees-of-freedoms (DOFs) of the structure, sensors are only installed on very limited stories, which makes the current seismic damage detection methods for real structures mainly focus on the story-level. The structure excited by strong ground motion will be in the nonlinear stage because the structural material yields under high stress and large deformation. The plastic hinges will exist at the ends of beams and columns, the cracks at components like beams, columns, and walls will open and close, and the forcedisplacement curves will show obvious hysteresis characteristics. These kinds of nonlinear behaviour of monitored structure make the damage detection methods based on linear system theory not suitable for detecting structural seismic damage. Thus, nonlinear indicator function methods, which belong to data-driven approaches, are proposed to detect these kinds of damages by extracting the nonlinear features in the dynamic vibration measurements. Farrar et al. gave a comprehensive review on damage detection using nonlinear system identification and nonlinear indicator functions approaches [15]. Due to the nonstationarity of measured structural responses, time-frequency distributions such as Wigner-Ville distribution and time-scale transforms such as wavelet transform have been implemented and widely used to analyse and interpret the nonstationary signals in timefrequency or time-scale domain. Staszewski and Robertson [16], Robertson and Basu [17], and Ceravolo [18] gave comprehensive reviews on using time-frequency and time-scale transforms for SHM. In this paper, references focused on wavelet transform were presented. Robertson et al. used the Holder index derived from the continuous wavelet transform to characterize the singularity of the structure due to nonlinearity and identified damage such as structural looseness, collisions, and cracks [19]. Civera et al. proposed a novel approach using bispectral analysis and neural network to identify the locations of breathing cracks in a cantilever beam [20]. Liew and Wang implemented wavelet theory to identify crack damage in structures, where discrete wavelet transform was used to decompose the vibrational shape of a simply supported cracked beam, and the crack location was identified by the variation of the imaginary parts of the $8^{\text {th }}$ and $9^{\text {th }}$ order wavelet coefficients [21]. Loh et al. used the first-order discrete wavelet coefficients, wavelet packet energy, and Holder index to identify the seismic damage of a single-story reinforced concrete structure in a shaking table test $[22,23]$. Vafaei and
Adnan used continuous wavelet transform to identify the simulated seismic damage of an airport traffic control tower and found that continuous wavelet transform had stronger noise immunity than discrete wavelet transform and did not need as high sampling frequency as discrete wavelet transform [24]. Kumar and Zanotti Fragonara proposed a time-frequency method to identify nonlinear characteristics of a cable element [25]. Nagarajaiah and Basu summarized the pros and cons of short time Fourier transform, wavelet transform, and Hilbert-Huang transform application in structural seismic damage detection [26]. The features of nonlinear system such as fractal dimension (FD) and chaos were also used as nonlinear indicator function [27-30]. Li et al. proposed a datadriven approach using the time-frequency feature (TFF) for shear-type buildings where the FD of TFF at each DOF for linear system was derived with the help of modal superposition principle, and the FD of TFF for each substructure in nonlinear system was derived with the help of substructure method [31]. Carrillo and Avila used FD of breathing cracks to assess the seismic damage of reinforced concrete walls [32].

In this paper, a data-driven approach using the timefrequency feature (TFF) of the interstory displacement is further developed for detecting story-level damage of moment resisting frame (MRF) structure subjected to earthquake. This nonlinear indicator function method was proposed by the author to detect seismic damage of sheartype buildings. For the integrity and understandability, some important principles and equations are also given in the paper. In Section 2.1, the real part of the Gabor wavelet transform is introduced to stand for the TFF. Section 2.2 uses the FD to quantify the random fractal set of TFF. Section 2.3 deduces the FD property of linear MRF using the definition of TFF and modal superposition technique. Section 2.4 deduces the FD property of damaged MRF with plastic hinges at the ends of beams and columns using the force analogy method, which establishes the relation between interstory inelastic displacements and plastic hinge rotations. Section 3 presents numerical simulations on a 16story 3-bay MRF to demonstrate the validity of the approach, and finally Section 4 gives the conclusions.

\section{Seismic Damage Detection Method of MRF Using the Time-Frequency Feature (TFF)}

2.1. TFF by Gabor Wavelet Transform. Wavelet transform is a well-developed time-frequency analysis tool, transforming time domain signal into time-frequency domain distribution and showing the frequency contents evolution. Unlike Fourier transform using the sine and cosine basis without time resolution, wavelet transform uses wavelets with good time and frequency localization and is good for analysing nonstationary signals like strong ground motion and structural response. Gabor wavelet is especially developed to demonstrate local time and frequency distribution since it minimizes the product of time resolution and frequency resolution. Gabor wavelet, as one kind of analytical wavelet, has the property that the real and imaginary part of the corresponding wavelet coefficients is a Hilbert transform pair. For other wavelet transform whose mother wavelet is 
not analytic, the above relationships are not true. The Gabor wavelet transform is given by [33]

$$
W x(b, a)=\int_{-\infty}^{\infty} x(t) \frac{1}{\sqrt{a}} \varphi^{*}\left(\frac{t-b}{a}\right) d t,
$$

where $x(t)$ is the time domain signal, $b$ is time, $a$ is scale, and $\varphi^{*}$ is the conjugate of Gabor wavelet given by

$$
\varphi(t)=\frac{1}{\left(\sigma^{2} \pi\right)^{1 / 4}} \exp \left(-\frac{t^{2}}{2 \sigma^{2}}+2 \pi j f_{0} t\right),
$$

where $j$ is the imaginary unit, $\sigma$ is the frequency bandwidth, and $f_{0}$ is the central frequency. The frequency in the timefrequency domain is given by the scale $a$, sampling frequency $f_{s}$, and central frequency $f_{0}$ as shown in the following equation:

$$
f=\frac{f_{\mathrm{s}} f_{0}}{a} .
$$

As deduced in Reference [31], the TFF is defined as the real part of Gabor wavelet transform in a chosen scale or frequency band given by

$$
F_{x}=\operatorname{Re}\left(W x(b, a) \mid a \in\left[a_{l} a_{h}\right]\right) .
$$

To keep the linear superposition of TFF and to suppress the interference between different modes, the real part, not the norm of the wavelet coefficients of the signal, is used in this study. Meanwhile, for most damage detection purpose, the scale is chosen within the fundamental frequency of the analysed structure. The TFF of the damaged structure will show much energy in the frequency band below the structural fundamental frequency. The TFF can be treated a matrix whose columns stand for time and rows for frequency, and it can be visualized as a three-dimensional (3D) surface.

\subsection{Fractal Dimension (FD) to Quantify Time-Frequency} Feature (TFF). To quantify the calculated TFF of a signal, FD is introduced. FD is an indicator for describing the complexity or irregularity of natural objects, textures, images, and signals [34]. Unlike deterministic fractal such as Koch curve or Sierpinski Triangle which has FD at any scale, the TFF is a kind of random fractal set which has FD only in specific scale. The FD of TFF is calculated using the box counting method given by

$$
\operatorname{dim}\left(F_{x}\right)=-c_{1},
$$

where $c_{1}$ is the regression coefficient given by

$$
\log \left(N_{\delta}\left(F_{x}\right)\right)=c_{1} \log (\delta)+c_{2},
$$

where $\delta$ is the side length of small box and $N_{\delta}$ is the minimal number of $\delta$-length small box to cover completely the $3 \mathrm{D}$ surface of TFF.

2.3. FD Property of Linear MRF Structure. MRF has translational and rotational vibration. As static condensation method points out, rotational vibration can be deduced by translational vibration if the inertial effect of beams is ignored. The motion equation for linear MRF is given by

$$
\begin{aligned}
& {\left[\begin{array}{cc}
M_{m m} & 0 \\
0 & 0
\end{array}\right]\left\{\begin{array}{c}
\ddot{X}_{m} \\
\ddot{X}_{s}
\end{array}\right\}+\left[\begin{array}{cc}
\alpha M_{m m}+\beta K_{m m} & \beta K_{m s} \\
\beta K_{s m} & \beta K_{s s}
\end{array}\right]\left\{\begin{array}{c}
\dot{X}_{m} \\
\dot{X}_{s}
\end{array}\right\}} \\
& +\left[\begin{array}{cc}
K_{m m} & K_{m s} \\
K_{s m} & K_{s s}
\end{array}\right]\left\{\begin{array}{c}
X_{m} \\
X_{s}
\end{array}\right\}=-\left[\begin{array}{cc}
M_{m m} & 0 \\
0 & 0
\end{array}\right] \ddot{x}_{g},
\end{aligned}
$$

where $X_{m}$ denotes displacement vector in the translational or master degree-of-freedom (DOF) and $X_{s}$ displacement vector in the rotational or secondary DOF; $\dot{X}_{m}, \dot{X}_{s}$ are the corresponding translational and rotational velocity vectors; $\ddot{X}_{m}, \ddot{X}_{s}$ are the corresponding translational and rotational acceleration vectors; $M_{m m}, K_{m m}$ are the translational block matrices of mass, stiffness matrices; $K_{s s}$ is the rotational stiffness matrices; $K_{m s}$ and $K_{s m}$ are the off-diagonal stiffness matrices; $\alpha, \beta$ are the Rayleigh proportional damping parameters, and $\ddot{x}_{g}$ is the ground motion acceleration. From Equation (7), the rotational or secondary displacement vector can be expressed as

$$
X_{s}=-K_{s s}^{-1} K_{s m} X_{m} \text {. }
$$

Substituting Equation (8) into (7), the static condensed motion equation is given by

$$
M^{e} \ddot{X}_{m}+C^{e} \dot{X}_{m}+K^{e} X_{m}=-M^{e} 1 \ddot{x}_{g},
$$

where $M^{e}, C^{e}, K^{e}$ are the effective mass, damping, and stiffness matrices giving by $M^{e}=M_{m m}, K^{e}=K_{m m}-$ $K_{m s} K_{s s}^{-1} K_{s m}$, and $C^{e}=\alpha M^{e}+\beta K^{e}$.

The relative translational displacements of the condensed linear MRF can be given as follows with the help of modal decomposition technique:

$$
X_{m}=\sum_{i=1}^{n} \mu_{i} q_{i}
$$

where $\mu_{i}=\left[\begin{array}{llll}\mu_{1 i} & \mu_{2 i} & \cdots & \mu_{N_{s} i}\end{array}\right]$ is the $i$ th mode shape vector, and $q_{i}$ is the $i$ th generalized modal displacement. Based on the definition of TFF, the following equation can be deduced:

$$
\begin{aligned}
F_{x_{m i}} & =\operatorname{Re}\left(W x_{m i}(b, a)\right) \\
& =\operatorname{Re}\left(\int_{-\infty}^{\infty} x_{m i}(t) \frac{1}{\sqrt{a}} \varphi^{*}\left(\frac{t-b}{a}\right) d t\right) \\
& =\operatorname{Re}\left(\int_{-\infty}^{\infty} \sum_{j=1}^{n} \mu_{i j} q_{j} \frac{1}{\sqrt{a}} \varphi^{*}\left(\frac{t-b}{a}\right) d t\right) \\
& =\sum_{j=1}^{n} \mu_{i j} F_{q_{j}} .
\end{aligned}
$$

Using the property of $\mathrm{FD}$, which is that the $\mathrm{FD}$ of a constant times a fractal is the same as the original fractal, the following equation can be deduced:

$$
\operatorname{dim}\left(F_{x_{m i, j}}\right)=\operatorname{dim}\left(\mu_{i j} F_{q_{j}}\right)=\operatorname{dim}\left(F_{q_{j}}\right),
$$

where $x_{m i, j}$ is the partial relative displacement at $i$ th translational DOF contributed by the $j$ th mode. From Equation (12), it can be seen that FD of TFF of all relative translational displacements of a MRF contributed by any 
given mode is identical to the FD of that generalized mode displacement.

2.4. FD Property of Damaged MRF Structure with Beam or Column Plastic Hinges. When MRF structure is excited by strong ground motion, plastic hinges will be formed at the ends of beams and columns. It is these plastic hinges that make the horizontal displacement of the structure contain inelastic displacements. The force analogy method establishes an explicit expression between the inelastic displacement and the plastic hinge rotation of the beams and columns. The force analogy method is a numerical method for solving dynamic responses of nonlinear structures. It was first proposed by Lin and developed and refined by Hart [35]. The traditional method to solve the structural dynamic response is to constantly correct the instantaneous stiffness of the structure. However, the force analogy method adjusts the inelastic displacement so that the total restoring force equals the total restoring force of the modified stiffness method. The translational displacement of the reduced MRF is given by

$$
X(t)=X^{e}(t)+X^{i e}(t),
$$

where $X^{e}(t)$ is the elastic displacement and $X^{i e}(t)$ is the inelastic displacement which is introduced by damage at the ends of beams and columns. The plastic rotation vector of the plastic hinges at the ends of beams and columns is defined as

$$
\Theta^{i e}(t)=\left[\theta_{1}^{i e}(t) \theta_{2}^{i e}(t) \cdots \theta_{n}^{i e}(t)\right]^{T},
$$

where $\theta_{i}^{i e}(t)$ is the plastic rotation at the $i$ th plastic hinge and $n$ is the total number of plastic hinges.

The nonequilibrium restoring force in the translational DOF generated by the plastic rotations at the ends of beams and columns is given by $-K_{P} \Theta^{i e}(t)$ where $K_{P}$ is called member force recovery matrix. The unbalanced bending moment generated at the beam-column joint is given by $-K_{R} \Theta^{i e}(t)$ where $K_{R}$ is called member restoring force matrix. $K_{P}$ and $K_{R}$ are the combination of corresponding matrix of each element. For an element with plastic hinges at both ends shown in Figure 1, the corresponding recovery matrices is given by

$$
\begin{aligned}
& K_{P}^{(i)}=\left[\begin{array}{cc}
\frac{6 E I}{L^{2}} & \frac{6 E I}{L^{2}} \\
\frac{4 E I}{L} & \frac{2 E I}{L} \\
-\frac{6 E I}{L^{2}} & -\frac{6 E I}{L^{2}} \\
\frac{2 E I}{L} & \frac{4 E I}{L}
\end{array}\right], \\
& K_{R}^{(i)}=\left[\begin{array}{cc}
\frac{4 E I}{L} & \frac{2 E I}{L} \\
\frac{2 E I}{L} & \frac{4 E I}{L}
\end{array}\right] .
\end{aligned}
$$

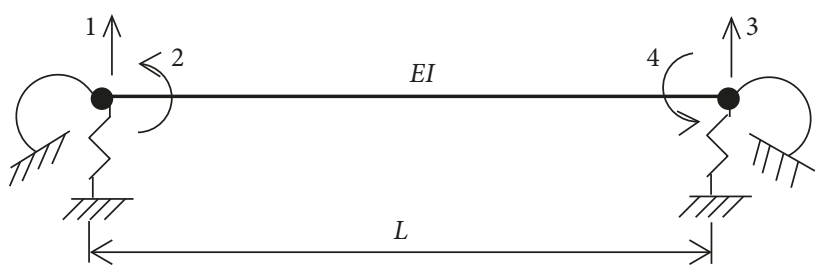

Figure 1: Element with plastic hinges at both ends.

From Figure 1 and Equation (15), it can be seen that only plastic hinges at the ends of columns produce horizontal inelastic displacement, and the plastic hinges at both ends of the beams do not produce horizontal inelastic displacement. The nonequilibrium restoring force caused by plastic hinges is balanced by the restoring force due to inelastic displacement:

$$
K X^{i e}+K_{P} \Theta^{i e}(t)=0 .
$$

Equation (16) gives the explicit expression between the inelastic displacement and the plastic hinge rotation of the beams and columns. Thus, the inelastic displacement at the master DOF of the reduced order frame structure can be deduced as

$$
X_{m}^{i e}(t)=\left(K^{e}\right)^{-1} K_{P}^{e} \Theta^{i e}(t),
$$

where $K_{P}^{e}=\left[I-\left(K_{s s}^{-1} K_{s m}\right)^{T}\right] K_{P}$ is the member force recovery matrix for the reduced order structure. If denoting a matrix $D$ as

$$
D=\left[\begin{array}{ccccc}
1 & 0 & 0 & \cdots & 0 \\
-1 & 1 & 0 & \cdots & 0 \\
& & \vdots & & \\
0 & \cdots & -1 & 1 & 0 \\
0 & 0 & \cdots & -1 & 1
\end{array}\right],
$$

then the explicit expression between interstory inelastic displacement in the master DOF and the plastic hinge rotation is given by

$$
\Delta X_{m}^{i e}(t)=D\left(K^{e}\right)^{-1} K_{P}^{e} \Theta^{i e}(t)=T \Theta^{i e}(t),
$$

where $T$ is a sparse transformation matrix from plastic hinge rotation to interstory inelastic displacement.

When the MRF structure is in linear stage and there is no plastic hinge at the ends of beams and columns, then, based on Equation (19), there is no interstory inelastic displacement in the master or translational DOFs, and the TFFs of interstory displacement in the master DOFs have the same FD. When plastic hinges occur at the ends of local beams and columns, due to sparseness of transformation matrix $T$, plastic hinges only generate inelastic displacements in the vicinity of the stories. Since the inelastic displacement belongs to low frequency signal, the TFFs of the interstory displacements with inelastic displacements are different from the TFF of the interstory displacements that do not contain inelastic displacements. Correspondingly, the FD of the TFF is also different from that of other stories, so as to determine the story location where exist plastic hinges at the ends of columns or beams. 


\section{Numerical Studies and Detection Results}

3.1. MRF Structural Model. The 3D finite element model was established by an open source software called the Open System for Earthquake Engineering Simulation (OpenSees) [36]. The simulated structural model was a 16-story steel MRF structure as shown in Figure 2, which was a 1:8 scale model of a real structure. The height of the story was $0.5 \mathrm{~m}$, and the total height of the structure was $8.0 \mathrm{~m}$. The MRF had three bays along the shaking direction with each span $0.75 \mathrm{~m}$ and one bay in the perpendicular direction with span $1.0 \mathrm{~m}$. The size of square column was $50 \times 50 \times 4 \mathrm{~mm}$, the size of the I-beam was $60 \times 4 \times 30 \times 5 \mathrm{~mm}$, the density of the steel was $7800 \mathrm{~kg} / \mathrm{m}^{3}$, the modulus of elasticity was $2.06 \times 10^{5} \mathrm{~N} / \mathrm{mm}^{2}$, and the additional mass at each story was $300 \mathrm{~kg}$. The beam and column elements were all made of Nonlinear BeamColumn elements. Inelastic fiber cross section was adopted for the element section. Axial hardening stress strain (Uniaxial Steel01) was chosen, the ratio of after-yield to preyield stiffness was 0.01 , and the Poisson ratio was taken as 0.3 . The damping of the entire structure was Rayleigh proportional damping, and the first-order and third-order modal damping ratios were 0.02 . The $3 \mathrm{D}$ finite element model ignored the rotational mass and vertical mass. The rigid diaphragm was turned off (RigidDiaphram OFF), and 5 Gaussian integration points were set in nonlinear curvature distribution of the element. Input ground motion used uniform excitation pattern, and the calculation step interval was $0.01 \mathrm{~s}$.

The input ground motions were chosen from PEER's NGA database. The record at El Centro site in October 15, 1979, Imperial Valley earthquake, was chosen as far-field strong ground motion. The record code was E12140. The PGA was 143 gal, the peak frequency was $1.76 \mathrm{~Hz}$, and the original sampling interval was $0.05 \mathrm{~s}$. This record was abbreviated as El Centro. The record at Ridge RT site, in January 18, 1994, Northridge earthquake, was chosen as near-field strong ground motion. The record code was ORR090. The PGA was 580 gal, the peak frequency was $1.22 \mathrm{~Hz}$, and the original sampling interval was $0.02 \mathrm{~s}$. This record was abbreviated as Northridge. In order to simulate no damage or different damage in specific stories, the chosen ground motions were scaled up or down, and the yielding stress of beams and columns were carefully set. The simulation included 10 cases such as no damage or linear structure, plastic hinges in single-story beams, plastic hinges in single-story columns, plastic hinges in single-story beams and columns, plastic hinges in multiple story beams, and columns as shown in Table 1 . The yielding stress at nonweak elements was set at $300 \mathrm{MPa}$ so that these elements would be not yielded.

3.2. Structural Seismic Damage Detection Results. To detect damage and locate the weak stories, the translational displacements at each translational DOF were extracted from the OpenSees dynamic response analysis. The plastic rotation at the ends of beams and columns were also extracted to demonstrate where the weak stories were truly located. The Gabor wavelet transform program used was WAVELAB, a MATLAB wavelet toolkit provided by David Donoho's group at Stanford
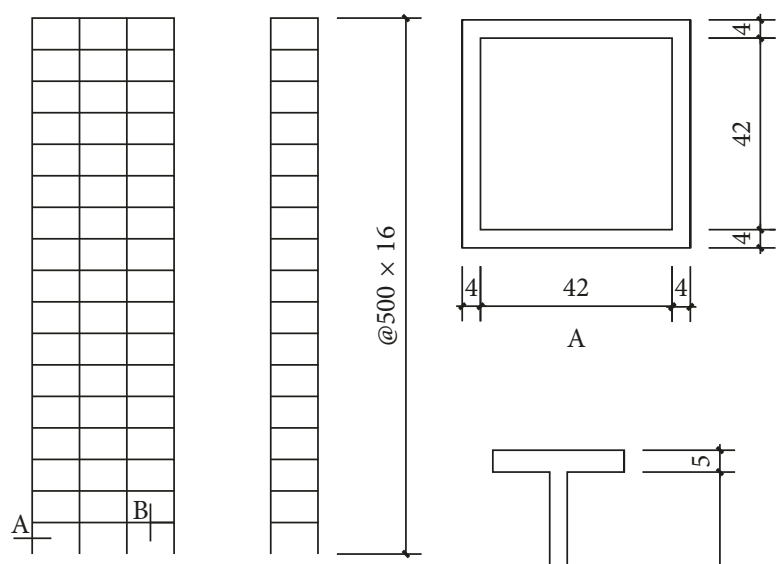

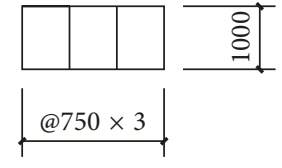

(a)

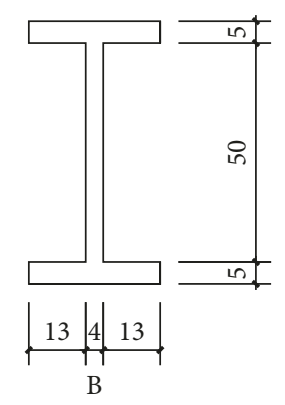

(b)
FIGURE 2: 16-story MRF structure model. (a) Geometrical size of the building (unit: $\mathrm{mm}$ ). (b) Section of columns and beams (unit: $\mathrm{mm})$.

University [37]. The FD calculation program used was FRACLAB, a MATLAB fractal toolkit provided by Canus et al. [38]. The central frequency of the Gabor wavelet was set $2.4 \mathrm{~Hz}$, which was close to the fundamental frequency of the simulated MRF structure, and the bandwidth was set 1 .

3.2.1. Linear Structure. In case 1 when the MRF structure was excited by $\mathrm{PGA}=28.6$ gal El Centro ground motion, the structure was in linear range without yielded element. The first two modal frequencies were $2.13 \mathrm{~Hz}$ and $6.53 \mathrm{~Hz}$, respectively. The contour map of time-frequency distribution, Fast Fourier Transform (FFT) spectra, and the interstory displacement is shown in Figure 3. For simplicity and concision, only the plots at $1^{\text {st }}, 7^{\text {th }}$, and $15^{\text {th }}$ stories were shown here. It could be seen from Figure 3 that the time-frequency distributions at these three stories were quite similar to each other. For the cut-off frequency of $0.1-4.0 \mathrm{~Hz}$, the log-log plot of the box counting of the TFF at the three stories is shown in Figure 4. The double logarithmic graph of the TFFs in the scale interval $2^{-5}-2^{-2}$ was approximately linear, indicating a fractal feature in this scale, and the corresponding FDs obtained by the least-squares method were 2.049, 2.048, and 2.049, respectively. The TFFs of the interstory displacement of other stories also had fractal features in this scale interval. The corresponding FDs are shown in Figure 5, and they were equal.

\subsubsection{Damaged Structure with Plastic Hinges in Single-Story}

Beams. In case 2 when the MRF structure was excited by $\mathrm{PGA}=429 \mathrm{gal} \mathrm{El}$ Centro ground motion, the structure was damaged with plastic hinges in the beams at the $1^{\text {st }}$ story. The rotation of plastic hinges at the ends of columns and beams 
TABLE 1: Location of nonlinearity and input ground motion.

\begin{tabular}{|c|c|c|}
\hline Case & Yielding stress at weak component & Input ground motion \\
\hline 1 & Beams and columns $205 \mathrm{MPa}$ & PGA $=28.6$ gal El Centro \\
\hline 2 & Beams at $1^{\text {st }}$ story $180 \mathrm{MPa}$, others $300 \mathrm{MPa}$ & PGA = 429 gal El Centro \\
\hline 3 & Columns at $1^{\text {st }}$ story $180 \mathrm{MPa}$, others $300 \mathrm{MPa}$ & PGA $=429$ gal El Centro \\
\hline 4 & Beams and columns at $1^{\text {st }}$ story $180 \mathrm{MPa}$, others $300 \mathrm{MPa}$ & $\mathrm{PGA}=429 \mathrm{gal} \mathrm{El} \mathrm{Centro}$ \\
\hline 5 & Beams and columns $205 \mathrm{MPa}$ & PGA = 715 gal El Centro \\
\hline 6 & Beams and columns $205 \mathrm{MPa}$ & PGA $=11.6$ gal Northridge \\
\hline 7 & Beams at $1^{\text {st }}$ story $180 \mathrm{MPa}$, others $300 \mathrm{MPa}$ & PGA $=348$ gal Northridge \\
\hline 8 & Columns at $1^{\text {st }}$ story $180 \mathrm{MPa}$, others $300 \mathrm{MPa}$ & PGA $=348$ gal Northridge \\
\hline 9 & Beams and columns at $1^{\text {st }}$ story $180 \mathrm{MPa}$, others $300 \mathrm{MPa}$ & PGA $=348$ gal Northridge \\
\hline 10 & Beams and columns $205 \mathrm{MPa}$ & PGA $=464$ gal Northridge \\
\hline
\end{tabular}

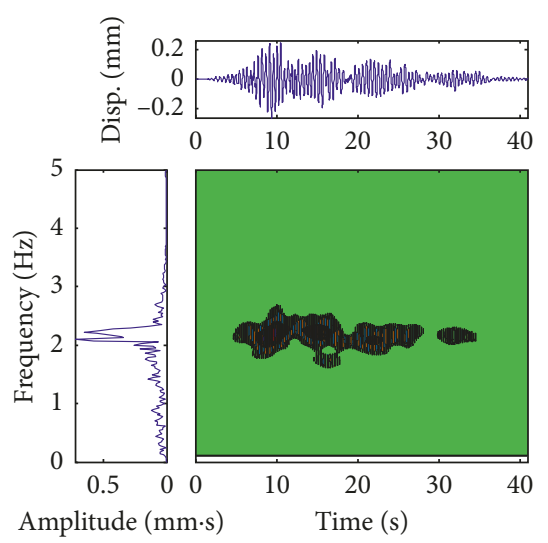

(a)

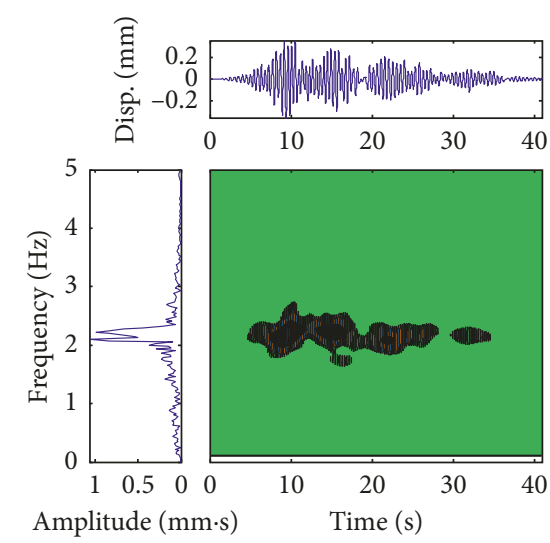

(b)

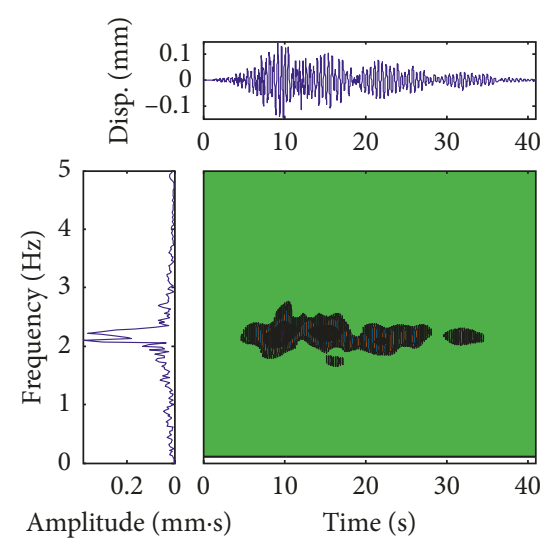

(c)

FIgUre 3: Time histories, TFFs, and the FFT spectra of interstory displacements of the structure under PGA = 28.6 gal El Centro ground motion (Case 1). (a) Story 1, (b) Story 7, and (c) Story 15.

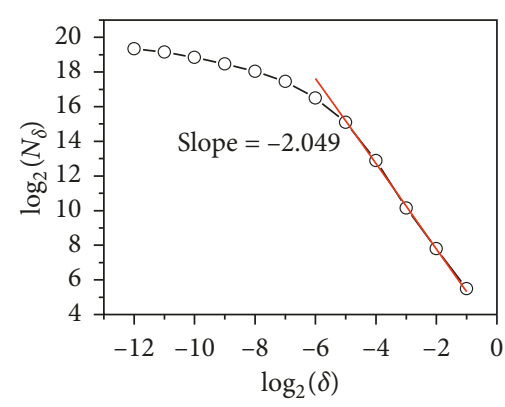

(a)

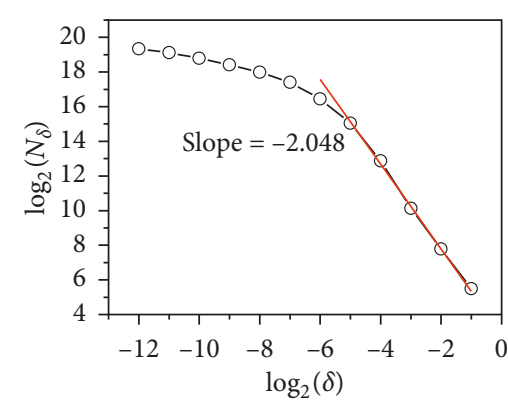

(b)

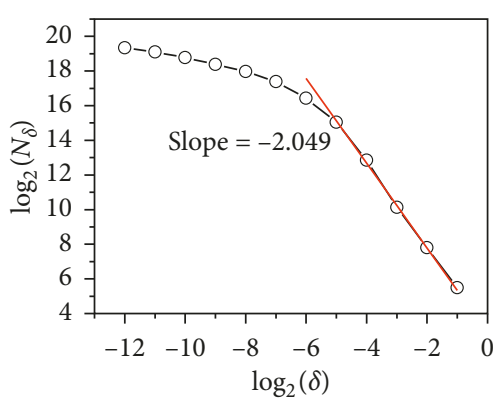

(c)

FIgURE 4: Log-log plot of the box counting of the TFF of the structure under PGA = 28.6 gal El Centro ground motion (Case 1). (a) Story 1, (b) Story 7, and (c) Story 15.

is shown in Figure 6, where columns A-D referred to the left column, left middle column, right middle column, and right column of the frame shown in Figure 2 and beams E-G referred to the left side beam, the centre beam, and the right side beam of the frame shown in Figure 2, and counts referred to the ends of the beams and columns. For example, counts in the column counted as 1 was to indicate the lower end of a column in the first story and 2 indicated the upper end of a column in the first story. The beam counted as 5 was to indicate the left end of a beam on the $3^{\text {rd }}$ story, 6 indicated the right end of a beam on the $3^{\text {rd }}$ story, and so on so forth.
From Figure 6, it could be seen that the beams at the $1^{\text {st }}$ story were damaged, and the columns at the $1^{\text {st }}$ story and beams and columns at other stories did not yield. The contour map of time-frequency distribution, FFT spectra, and the interstory displacement is shown in Figure 7, from which it could be seen that time-frequency distribution at the $1^{\text {st }}$ story was different from those at other stories, especially between 1.2 and $1.5 \mathrm{~Hz}$ in the frequency range and 10 and $12 \mathrm{~s}$ in the time range. The corresponding FDs in the scale interval $2^{-5}-2^{-2}$ were 2.092, 2.073, and 2.073 as shown in Figure 8. The FDs of TFFs at other stories are shown in Figure 9. The FDs of TFF at 


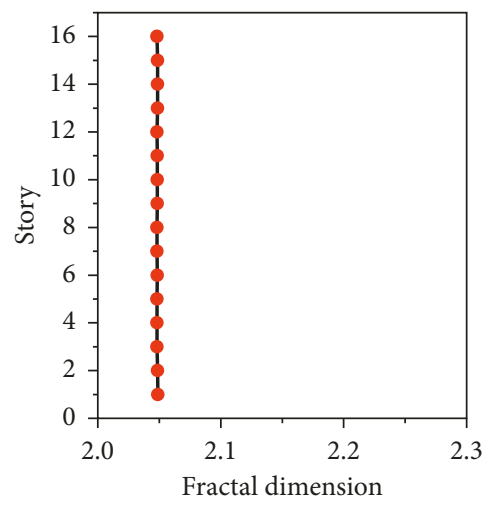

Figure 5: FDs of the TFFs of interstory displacements of the structure under PGA = 28.6 gal El Centro ground motion (Case 1).

the $1^{\text {st }}$ and $2^{\text {nd }}$ stories were a little different from those at other stories, and this is because plastic hinges introduced inelastic displacement at the $1^{\text {st }}$ story as inferred from Equation (19).
3.2.3. Damaged Structure with Plastic Hinges in Single-Story Columns. In case 3 when the MRF structure was excited by $\mathrm{PGA}=429$ gal El Centro ground motion, the structure was damaged with plastic hinges in the columns at the $1^{\text {st }}$ story. The rotation of plastic hinges at the ends of columns and beams is shown in Figure 10, from which it could be seen that the columns at the $1^{\text {st }}$ story were damaged and the beams at the $1^{\text {st }}$ story and beams and columns at other stories did not yield. The contour map of time-frequency distribution, FFT spectra, and the interstory displacement is shown in Figure 11, from which it could be seen that timefrequency distribution at the $1^{\text {st }}$ story was quite different from those at other stories, especially between 1.2 and $1.7 \mathrm{~Hz}$ in the frequency range and 8 and $12 \mathrm{~s}$ in the time range. The corresponding FDs in the scale interval $2^{-5}-2^{-2}$ were 2.134 , 2.070, and 2.071 as shown in Figure 12. The FDs of TFFs at other stories are shown in Figure 13. The FD of TFF at the $1^{\text {st }}$ story was quite different from those at other stories, and this could be interpreted by the transformation matrix $T$ given by

$$
T=\left[\begin{array}{cccccccc}
-0.1062 & -0.1002 & -0.1002 & -0.1062 & 0.0484 & 0.0603 & 0.0603 & 0.0484 \\
-0.1062 & -0.0429 & -0.0429 & -0.1062 & -0.0147 & -0.0036 & -0.0036 & -0.0147 \\
-0.0055 & -0.0057 & -0.0057 & -0.0055 & -0.0009 & -0.0013 & -0.0013 & -0.0009 \\
-0.0008 & -0.0007 & -0.0007 & -0.0008 & -0.0003 & -0.0001 & -0.0001 & -0.0003 \\
-0.0001 & -0.0001 & -0.0001 & -0.0001 & 0.0000 & 0.0000 & 0.0000 & 0.0000 \\
0_{11 \times 1} & 0_{11 \times 1} & 0_{11 \times 1} & 0_{11 \times 1} & 0_{11 \times 1} & 0_{11 \times 1} & 0_{11 \times 1} & 0_{11 \times 1}
\end{array}\right] .
$$

The coefficients at the first row were much higher than those at other rows, which meant the plastic hinges in the columns at the $1^{\text {st }}$ story mainly caused interstory inelastic displacement at the $1^{\text {st }}$ story, and thus, the FD of TFF at the $1^{\text {st }}$ story was different from others.

3.2.4. Damaged Structure with Plastic Hinges in Single-Story Beams and Columns. In case 4 when the MRF structure was excited by $\mathrm{PGA}=429 \mathrm{gal} \mathrm{El}$ Centro ground motion, the structure was damaged with plastic hinges in the beams and columns at the $1^{\text {st }}$ story. The rotation of plastic hinges at the ends of columns and beams is shown in Figure 14, from which it could be seen that the beams and columns at the $1^{\text {st }}$ story were damaged and the beams and columns at other stories did not yield. The contour map of time-frequency distribution, FFT spectra, and the interstory displacement is shown in Figure 15, from which it can be seen that time-frequency distribution at the $1^{\text {st }}$ story was quite different from those at other stories, especially between 0 and $1.0 \mathrm{~Hz}$ in the frequency range and 5 and $20 \mathrm{~s}$ in the time range. The corresponding FDs in the scale interval $2^{-5}-2^{-2}$ were $2.172,2.070$, and 2.071 as shown in Figure 16. The FD of TFF at other stories is shown in Figure 17. The FDs of TFFs at the $1^{\text {st }}$ story were quite different from those at other stories, and it was because the plastic hinges in the beams and columns at the $1^{\text {st }}$ story mainly caused interstory inelastic displacement at the $1^{\text {st }}$ story.
3.2.5. Damaged Structure with Plastic Hinges in MultipleStory Beams and Columns. In case 5 when the MRF structure was excited by PGA $=715$ gal El Centro ground motion, the structure was damaged with plastic hinges in the beams and columns at multiple stories. The rotation of plastic hinges at the ends of columns and beams is shown in Figure 18, from which it could be seen that the columns at Stories 1-6 and beams at Stories 1-10 were damaged. The contour map of time-frequency distribution, FFT spectra, and the interstory displacement is shown in Figure 19, where the plots at Stories 1-7 and 10 and 15 were shown here to demonstrate the behaviour of widespread damages in the frame. From Figure 19, it can be seen that timefrequency distribution at Stories 1-6 were quite different from those at other stories, especially between 0 and $1.0 \mathrm{~Hz}$ in the frequency range and 5 and $25 \mathrm{~s}$ in the time range. The low frequencies generated by plastic hinges at beams and columns were obvious in the lower stories especially in Stories 1-6, and disappeared in the upper stories. The corresponding FDs in the scale interval $2^{-5}-2^{-2}$ were 2.230, $2.228,2.222,2.206,2.179,2.141,2.119,2.120$, and 2.123 as shown in Figure 20. The FDs of TFFs at other stories are shown in Figure 21. The FDs of TFFs at Stories 1-6 were quite different from those at other stories, and it was because the plastic hinges in the beams and columns at Stories 1-6 mainly caused interstory inelastic displacement at Stories 1-6. 


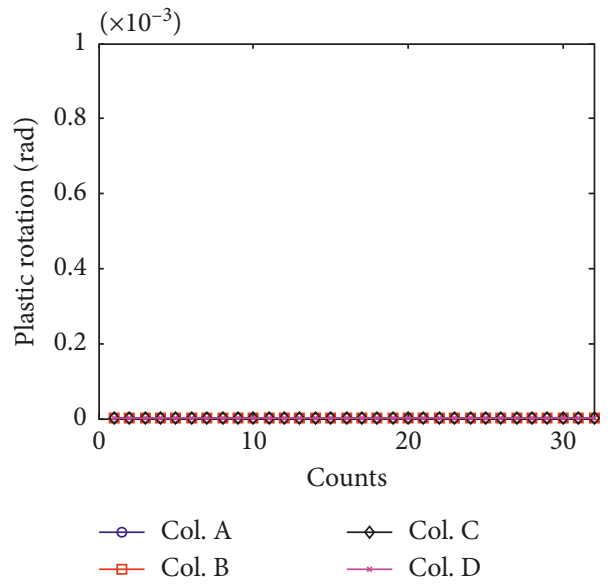

(a)

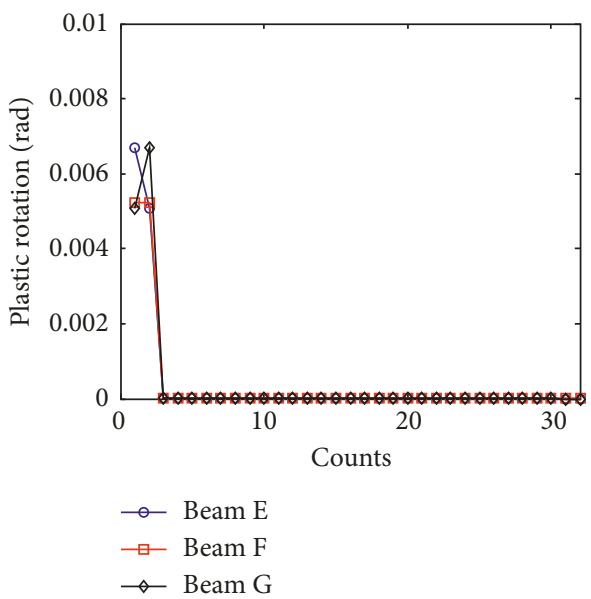

(b)

Figure 6: Rotation of plastic hinges at the ends of columns and beams under PGA $=429$ gal El Centro ground motion (Case 2). (a) Rotation of plastic hinges at the ends of columns. (b) Rotation of plastic hinges at the ends of beams.
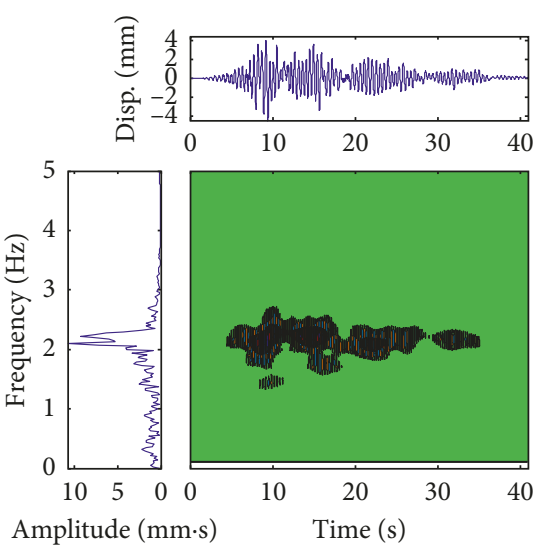

(a)
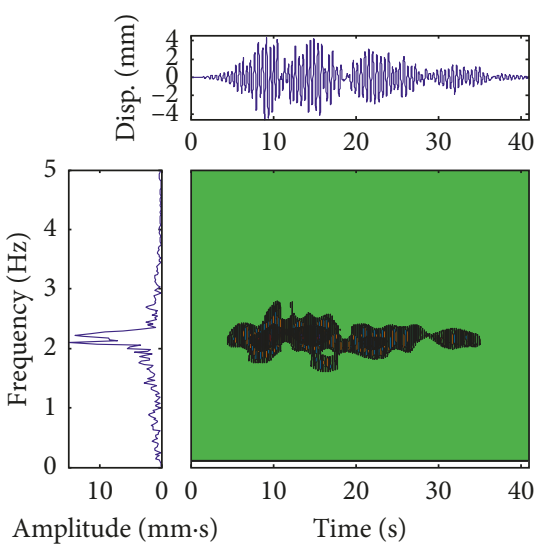

(b)
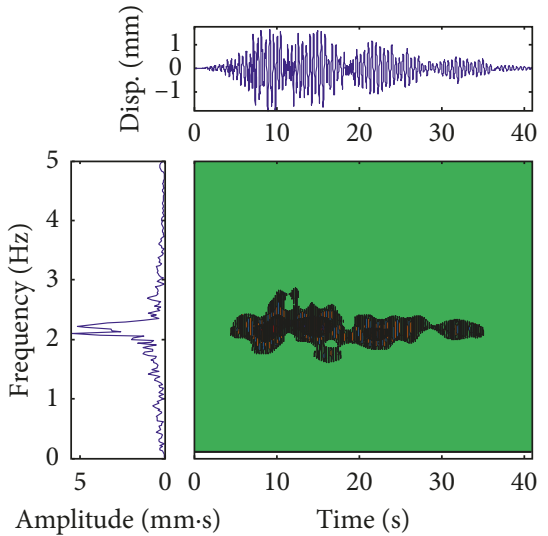

(c)

Figure 7: Time histories, TFFs, and the FFT spectra of interstory displacements of the structure under PGA $=429$ gal El Centro ground motion (Case 2). (a) Story 1, (b) Story 7, and (c) Story 15.

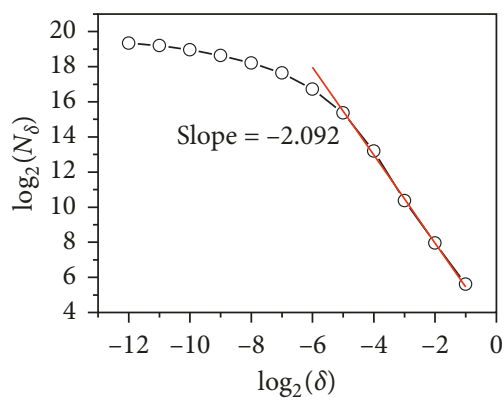

(a)

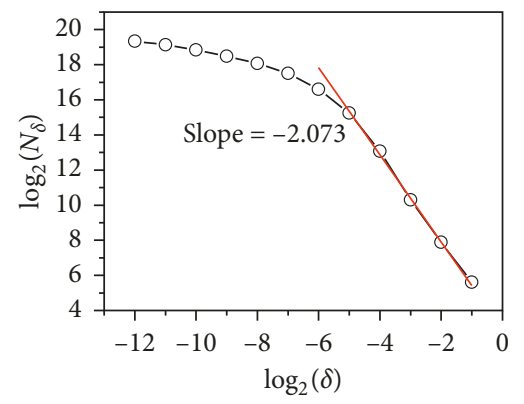

(b)

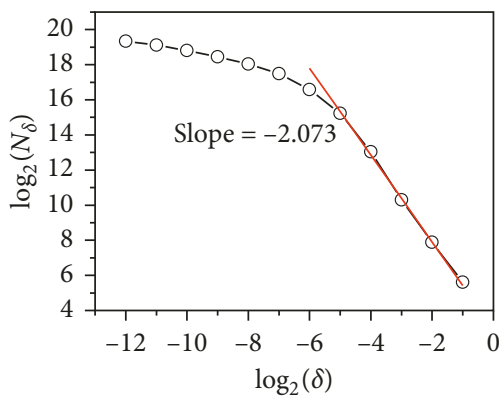

(c)

FIgURE 8: Log-log plot of the box counting of the TFF of the structure under PGA $=429$ gal El Centro ground motion (Case 2). (a) Story 1, (b) Story 7, and (c) Story 15.

To investigate the robustness of the approach to measurement noise, white Gaussian noise with 5\%, 10\%, $15 \%$, and $20 \%$ root mean square (RMS) noise-to-signal were added to the relative displacements at each story. The results for Case 5 are shown here. Time histories, TFFs, and the FFT spectra of the interstory displacement at Story 1 


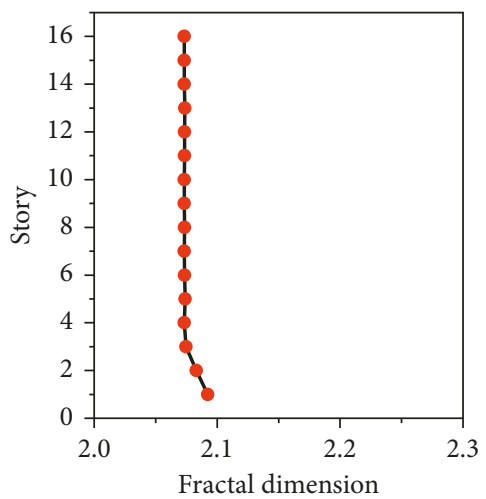

FIgURE 9: FDs of the TFFs of interstory displacements of the structure under PGA $=429$ gal El Centro ground motion (Case 2).

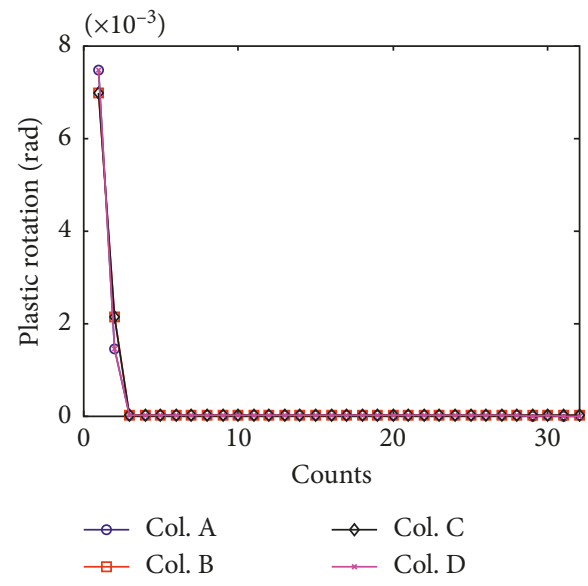

(a)

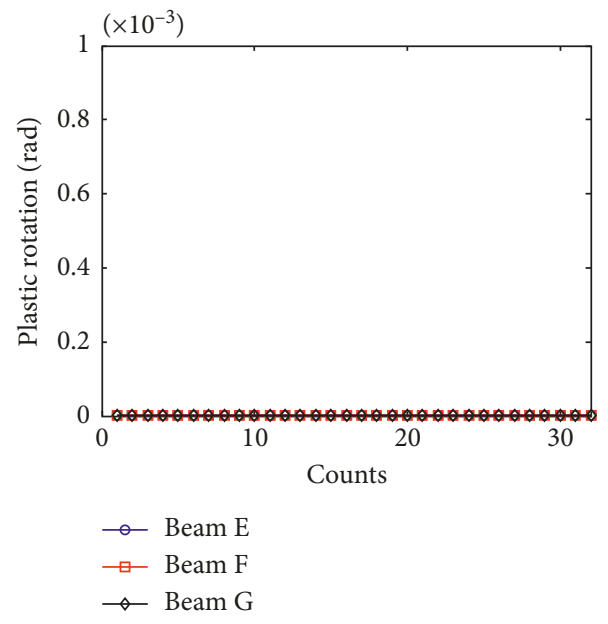

(b)

FIgURe 10: Rotation of plastic hinges at the ends of columns and beams under PGA $=429$ gal El Centro ground motion (Case 3). (a) Rotation of plastic hinges at the ends of columns. (b) Rotation of plastic hinges at the ends of beams.
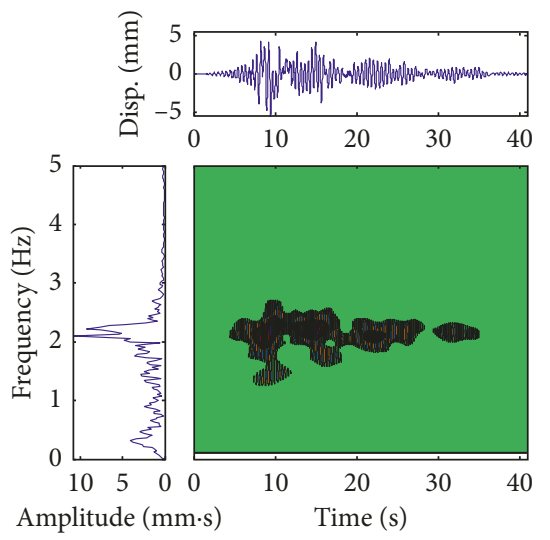

(a)
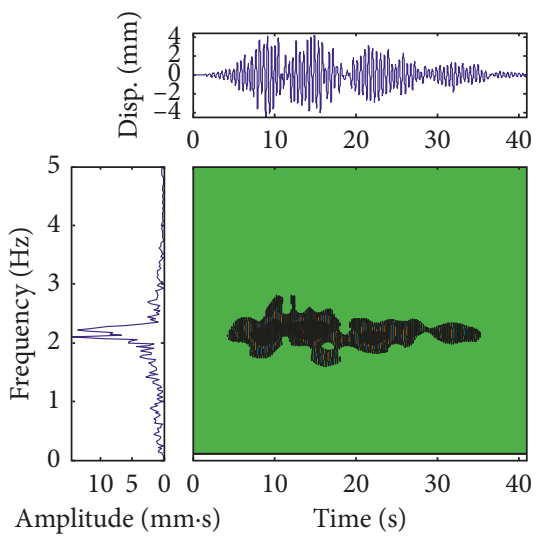

(b)
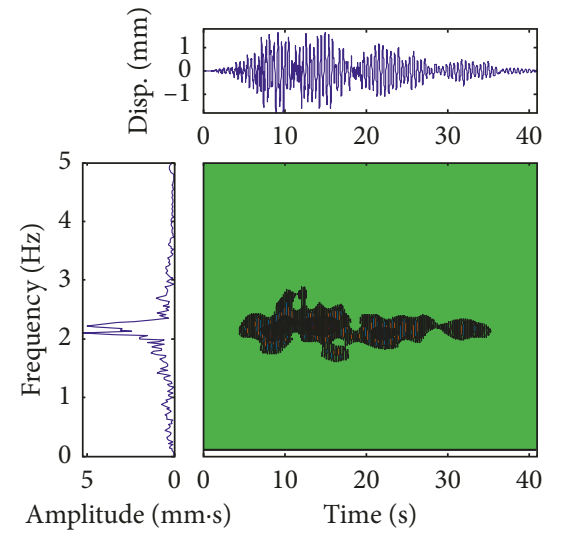

(c)

Figure 11: Time histories, TFFs, and the FFT spectra of interstory displacements of the structure under PGA $=429$ gal El Centro ground motion (Case 3). (a) Story 1, (b) Story 7, and (c) Story 15.

under different noise levels are shown in Figure 22. Though the time series under different noise level were different, the TFFs were quite similar even under $20 \%$ noise level. The calculated FDs of the TFFs of interstory displacements under different noise levels are shown in Figure 23, from which it can be seen that the results under 5\% and $10 \%$ 


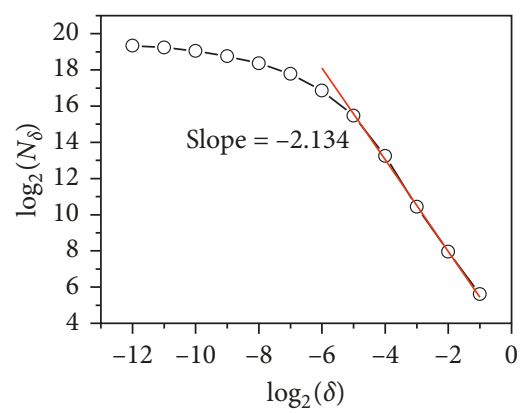

(a)

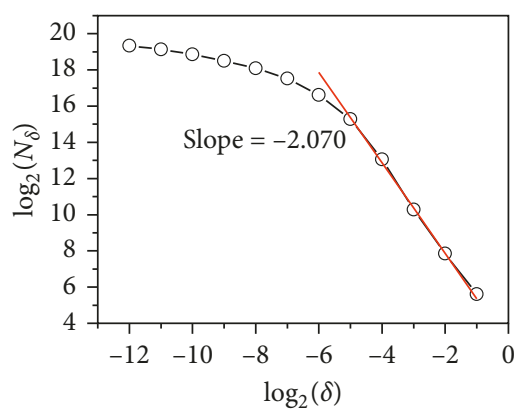

(b)

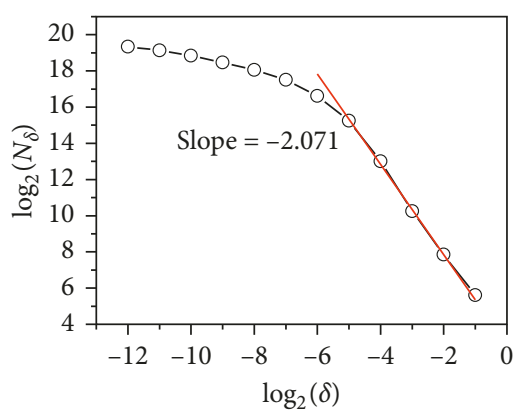

(c)

FIGURE 12: Log-log plot of the box counting of the TFF of the structure under PGA $=429$ gal El Centro ground motion (Case 3). (a) Story 1, (b) Story 7, and (c) Story 15.

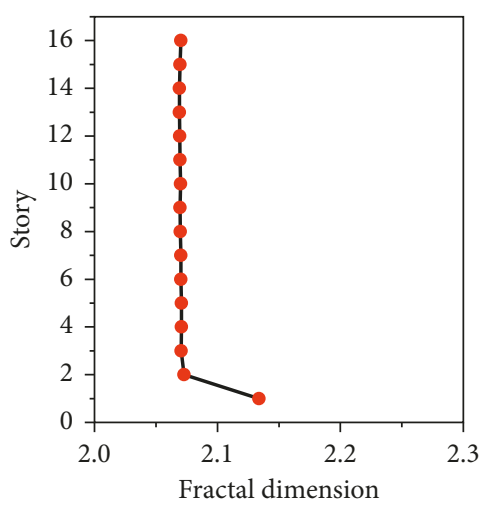

FIgURE 13: FDs of the TFFs of interstory displacements of the structure under PGA $=429$ gal El Centro ground motion (Case 3).

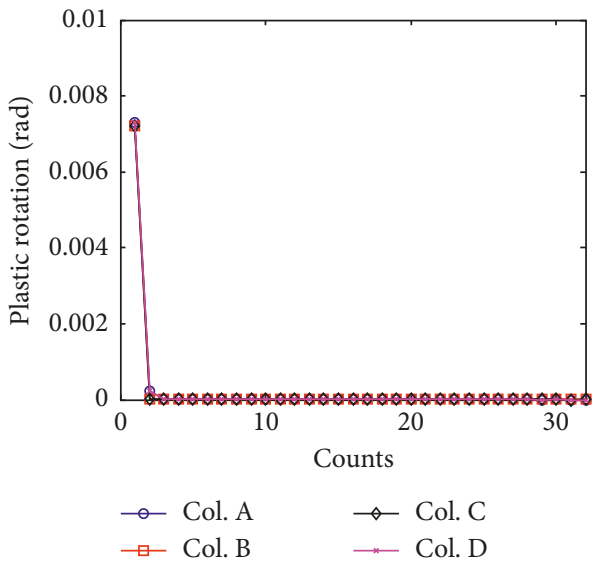

(a)

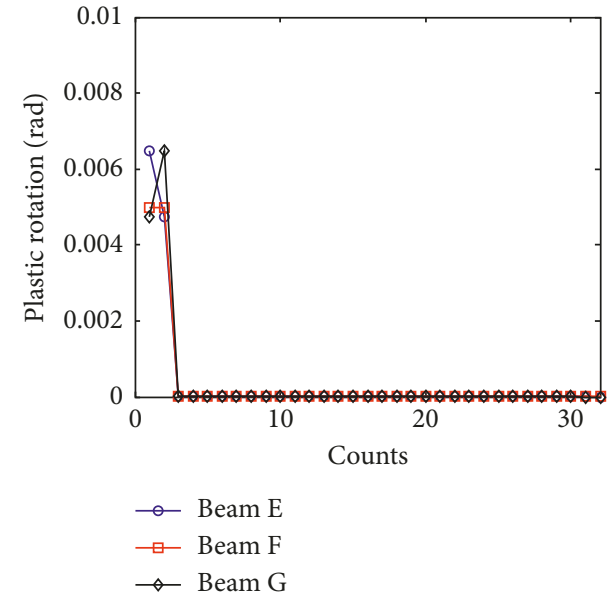

(b)

FIGURE 14: Rotation of plastic hinges at the ends of columns and beams under PGA $=429$ gal El Centro ground motion (Case 4 ). (a) Rotation of plastic hinges at the ends of columns. (b) Rotation of plastic hinges at the ends of beams.

noise levels were quite the same as those without noise. When the noise level became 15\%, the FDs at lower stories deviated from those values without noise, but it still could be deduced that the lower stories from Stories 1-10 were damaged and the upper stories from Stories 11-16 were not damaged. When the noise level became 20\%, the FD along the structure was a zigzag line which may be caused by damage or high-level noise, and the damage could not be determined.

3.2.6. Detection Result for Other Cases Studies under Other Ground Motions. The results of the FDs of the TFFs of the MRF structure for Cases 6-10 under Northridge ground 


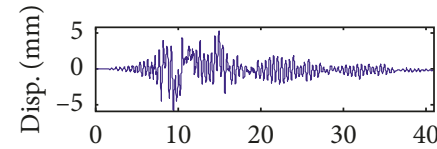

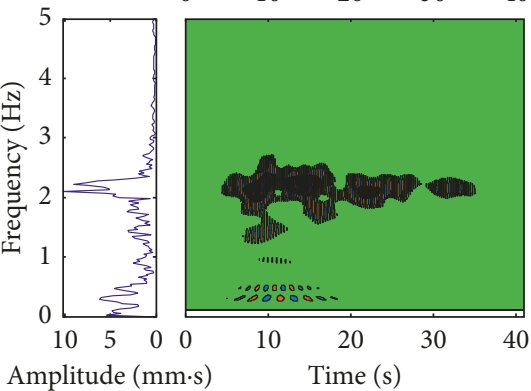

(a)
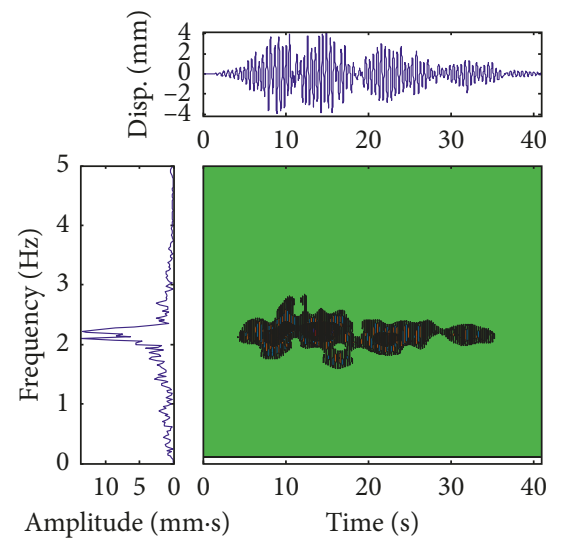

(b)

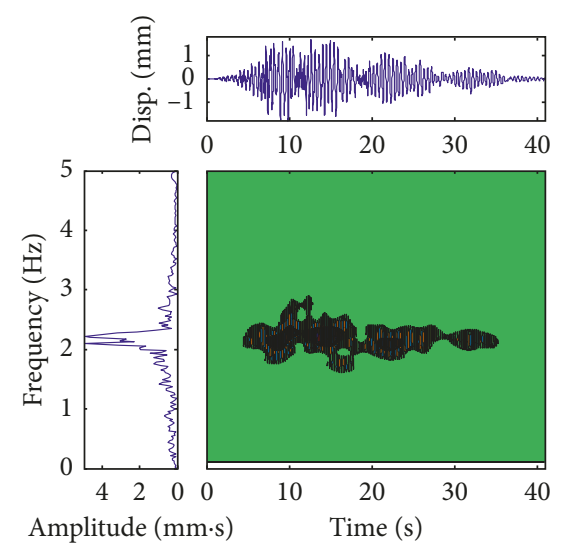

(c)

FIgURE 15: Time histories, TFFs, and the FFT spectra of interstory displacements of the structure under PGA $=429$ gal El Centro ground motion (Case 4). (a) Story 1, (b) Story 7, and (c) Story 15.

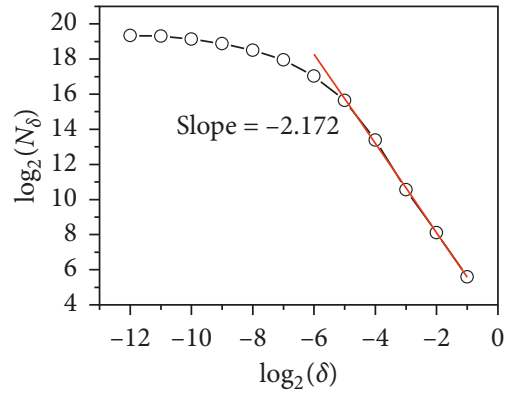

(a)

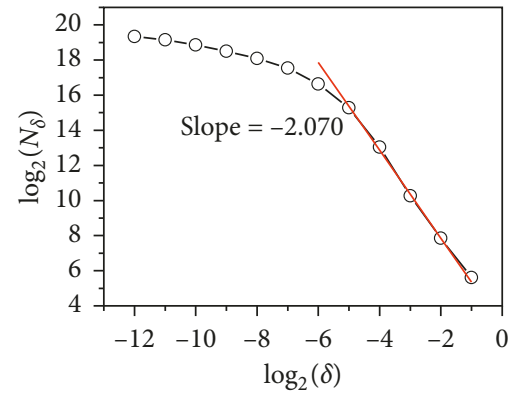

(b)

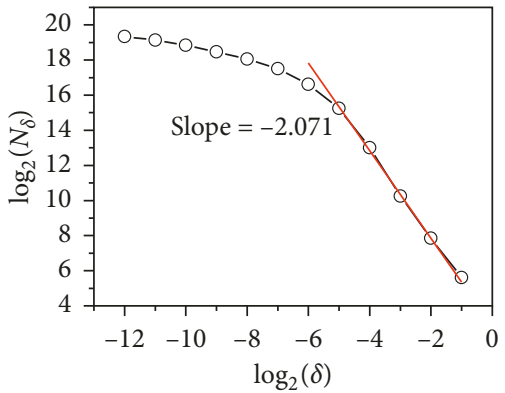

(c)

Figure 16: Log-log plot of the box counting of the TFF of the structure under PGA $=429$ gal El Centro ground motion (Case 4). (a) Story 1, (b) Story 7, and (c) Story 15.

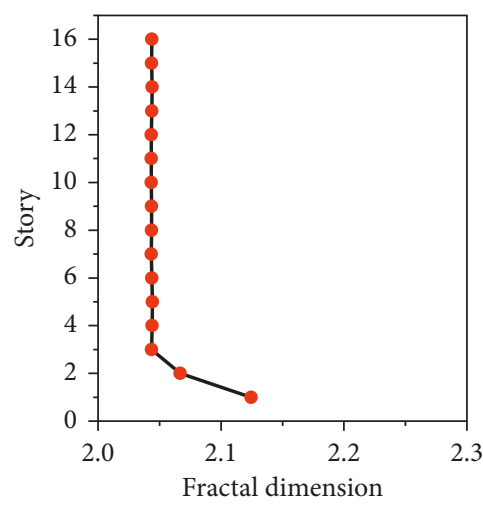

FIGURE 17: FDs of the TFFs of interstory displacements of the structure under PGA $=429$ gal El Centro ground motion (Case 4).

motion are shown in Figure 24 where all the extracted translational displacements were added 10\% RMS noise-tosignal white Gaussian noise, and similar results as the structure subjected to El Centro ground motion were obtained.

The damage detection results for the MRF excited by other strong ground motions were also investigated. The ground motions included TCU052W in September 20, 1999, Chichi earthquake abbreviated as Chichi, CUE90 in January 16, 1995, Kobe earthquake abbreviated as Kobe, C02065 in June 28, 1966, Parkfield earthquake abbreviated as Parkfield, and TAF111 in July 21, 1952, Kern County earthquake abbreviated as Taft, and the time histories and FFT spectra thereof are shown in Figure 25. To simulate different damage level, these ground motions were scaled up or down, and the time interval was set as 0.0035 second. For the cases when the yielding stresses at weak components were chosen as beams and columns $205 \mathrm{MPa}$, the detection results are shown in Figure 26.

The results when the structure was subjected to Chichi, Kobe, and Parkfield ground motions were similar as the results when subjected to El Centro or Northridge ground motions, and it could be seen that the lower stories were damaged in these cases. However, the FD of TFFs under Taft ground motion along the structure was a zigzag line, and it could be seen that the structure was damaged but the location of damage could not be determined. According to the definition of TFF given by Equation (4), the TFF was carefully chosen so that the frequency in the TFF was around or below the fundamental frequency of the analysed structure. If the chosen TFF was contaminated by higher 


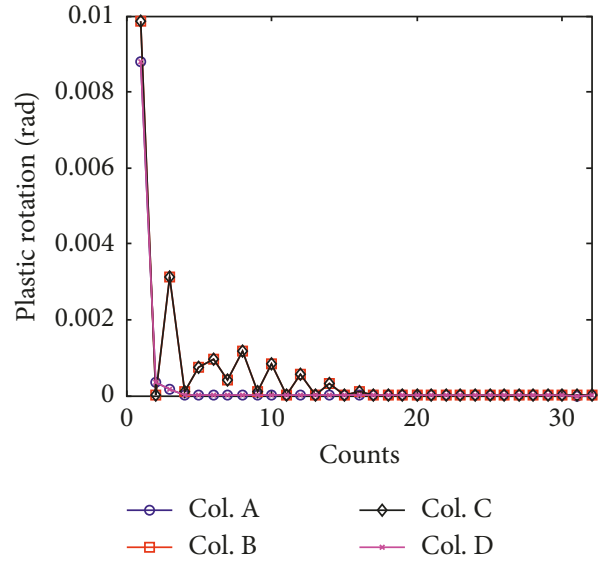

(a)

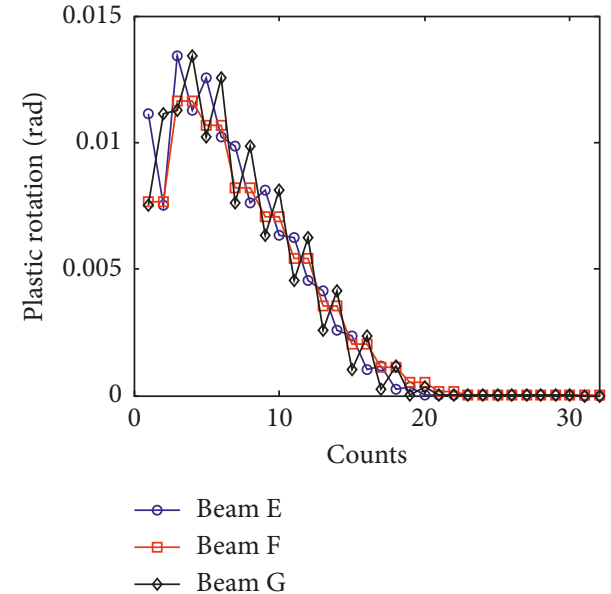

(b)

FIGURE 18: Rotation of plastic hinges at the ends of columns and beams under PGA $=715$ gal El Centro ground motion (Case 5). (a) Rotation of plastic hinges at the ends of columns. (b) Rotation of plastic hinges at the ends of beams.
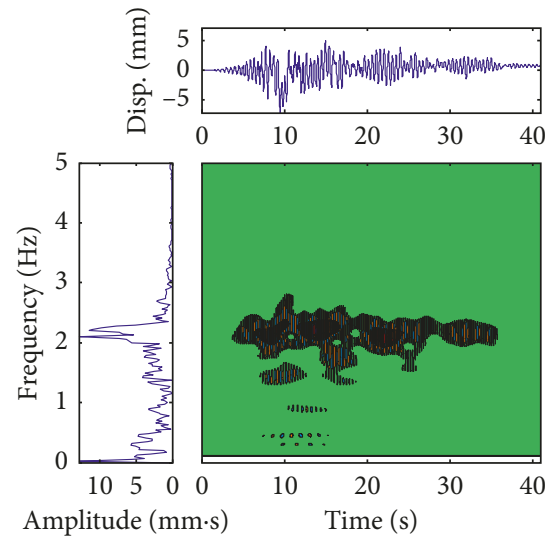

(a)
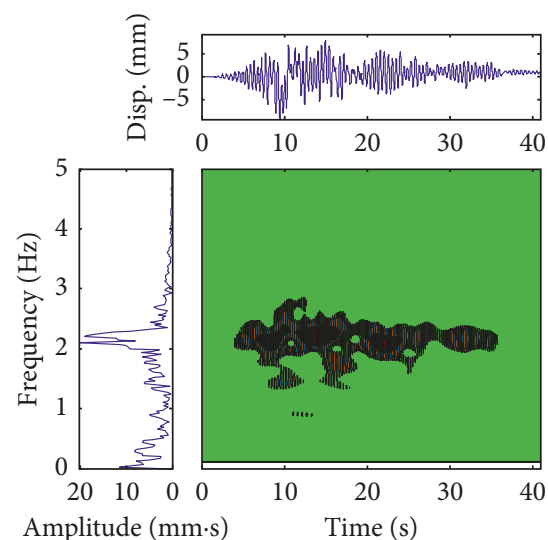

(d)

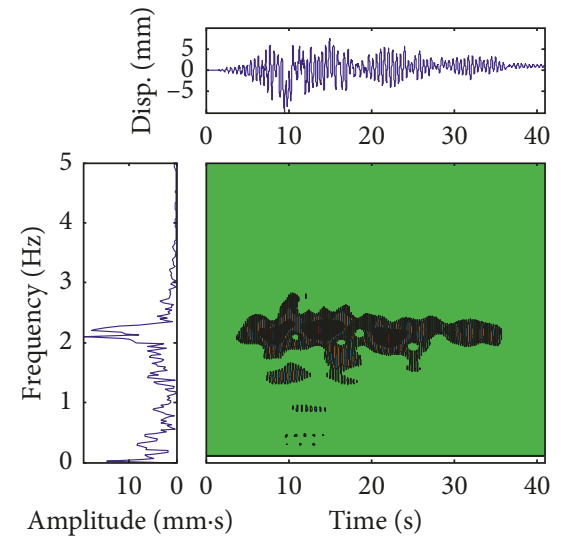

(b)

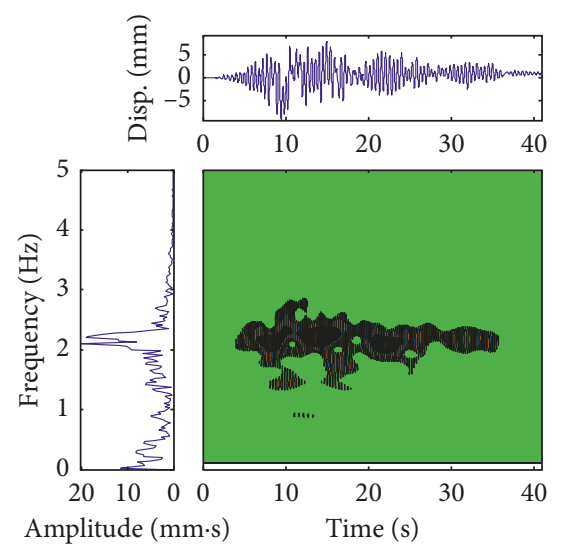

(e)

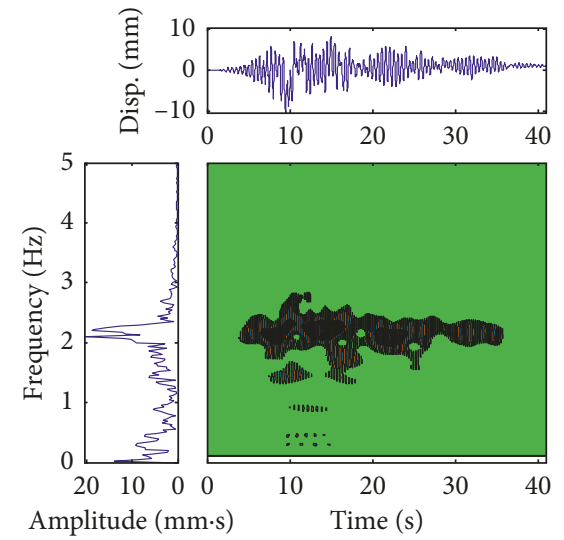

(c)

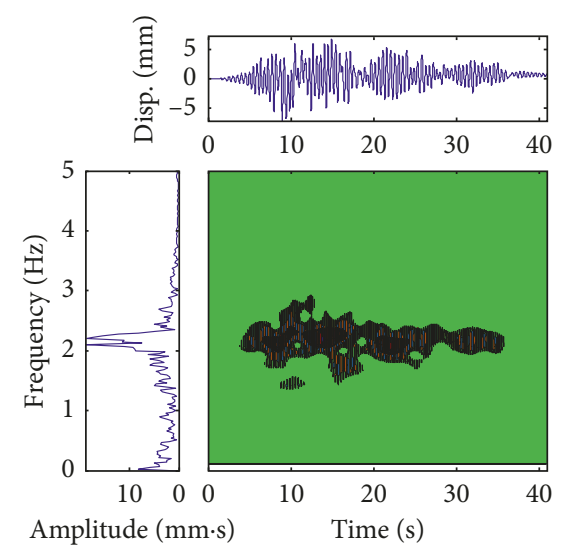

(f)

FIGURE 19: Continued. 


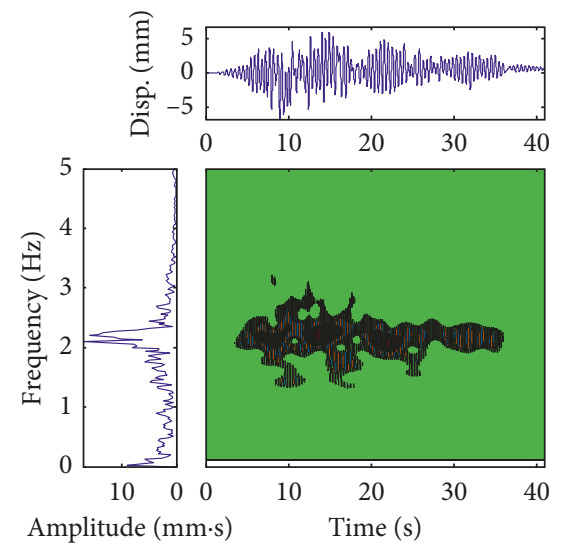

(g)

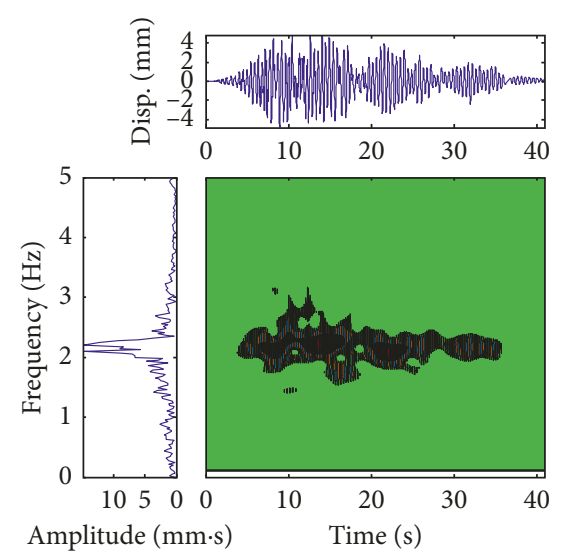

(h)

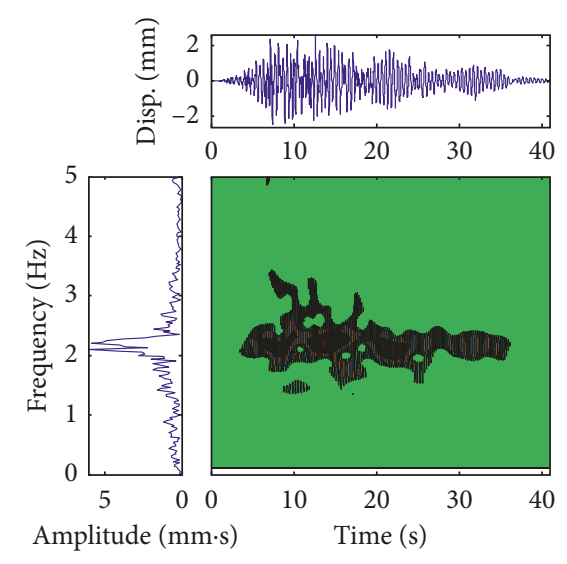

(i)

Figure 19: Time histories, TFFs and the FFT spectra of interstory displacements of the structure under PGA $=715$ gal El Centro ground motion (Case 5). (a) Story 1, (b) Story 2, (c) Story 3, (d) Story 4, (e) Story 5, (f) Story 6, (g) Story 7, (h) Story 10, and (i) Story 15.

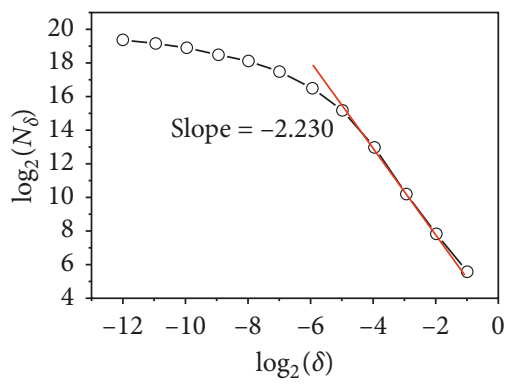

(a)

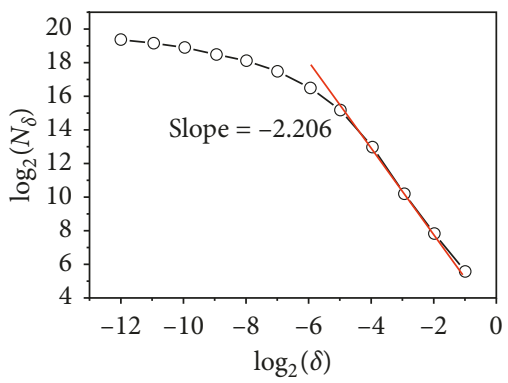

(d)

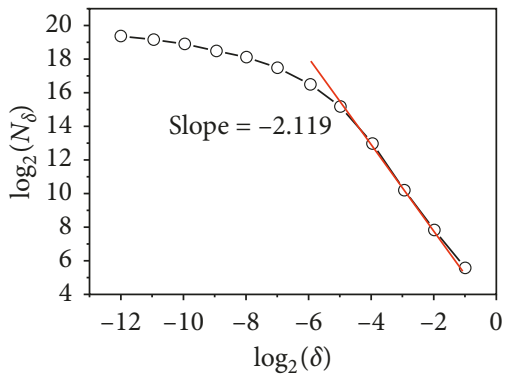

(g)

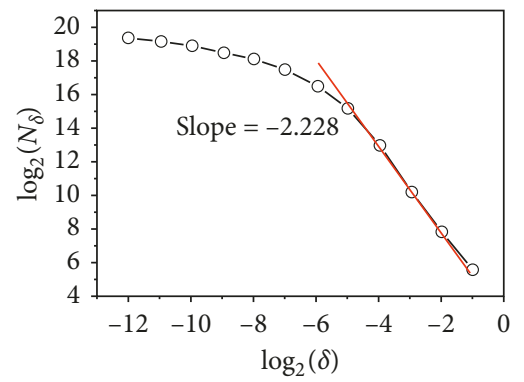

(b)

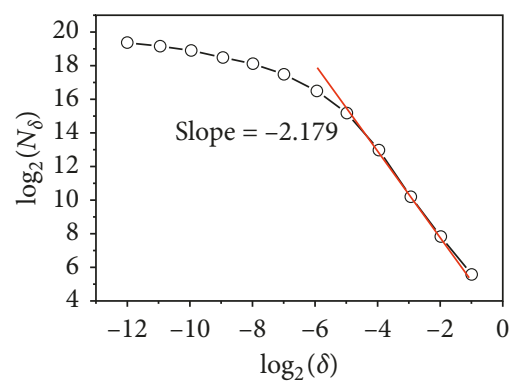

(e)

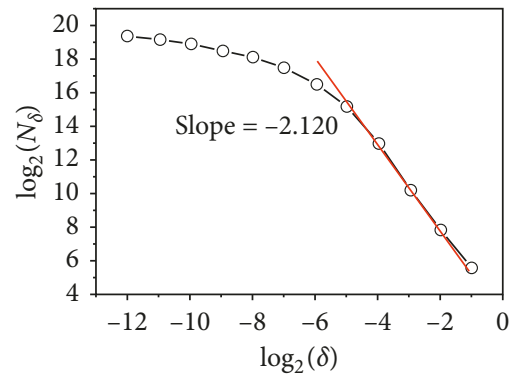

(h)

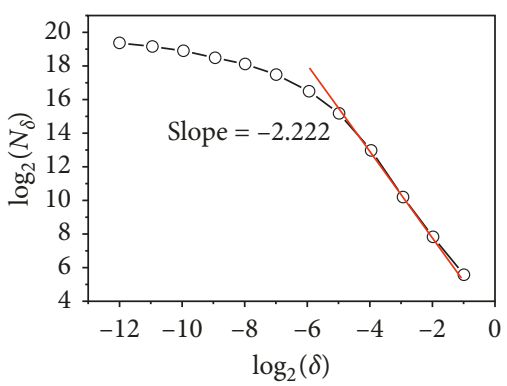

(c)

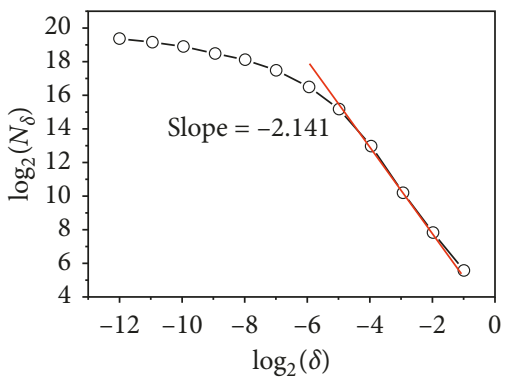

(f)

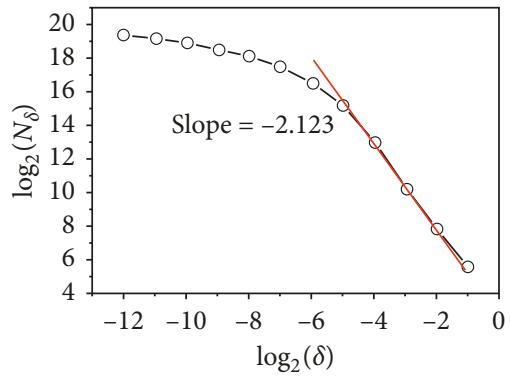

(i)

FIgURe 20: Log-log plot of the box counting of the TFF of the structure under PGA $=715$ gal El Centro ground motion (Case 5). (a) Story 1, (b) Story 2, (c) Story 3, (d) Story 4, (e) Story 5, (f) Story 6, (g) Story 7, (h) Story 10, and (i) Story 15. 


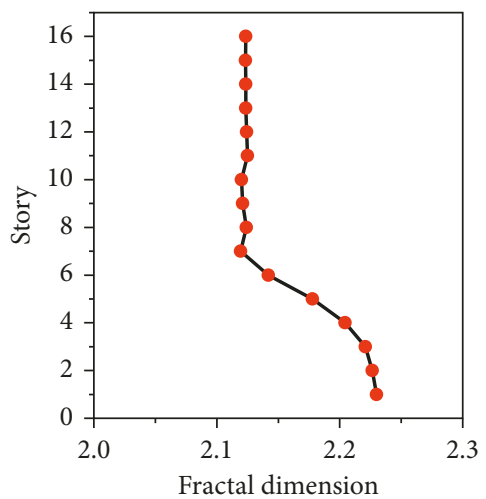

FIgURE 21: FDs of the TFFs of interstory displacements of the structure under PGA $=715$ gal El Centro ground motion (Case 5).
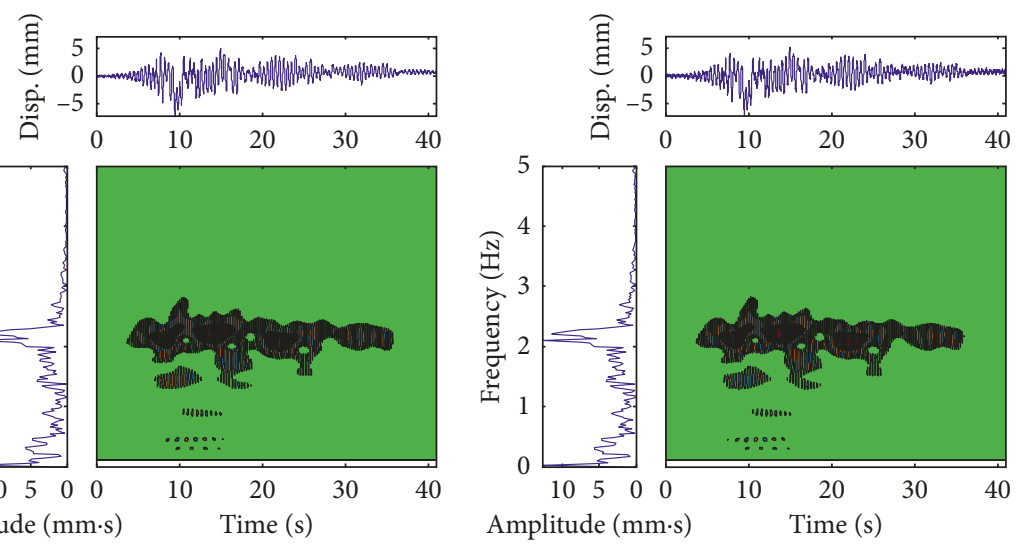

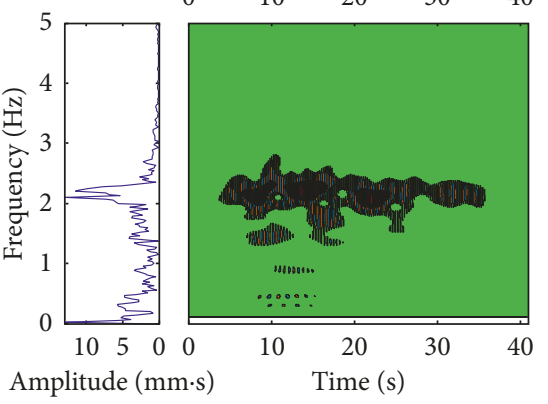

(a)

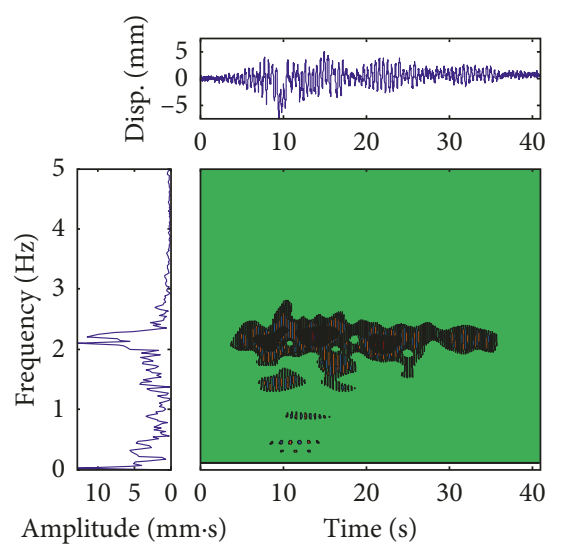

(c) (b)

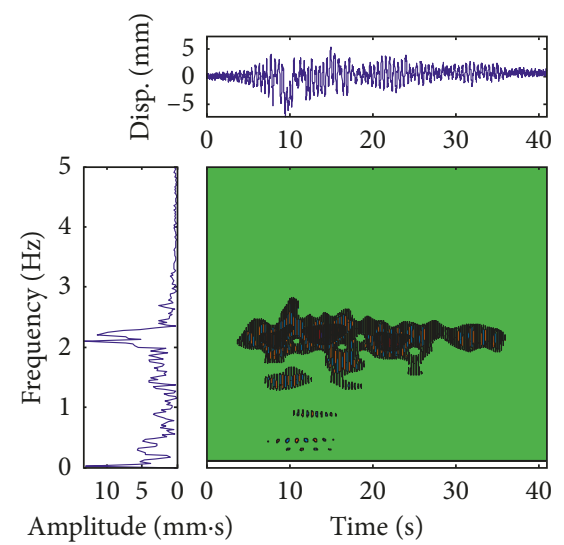

(d)

Figure 22: Time histories, TFFs, and the FFT spectra of interstory displacements at Story 1 under different noise levels (Case 5). (a) Noise level of 5\%, (b) noise level of 10\%, (c) noise level of 15\%, and (d) noise level of $20 \%$.

order frequency energy, the FD based approach would not give correct detection results. The first two modal frequencies of the MRF was 2.13 and $6.53 \mathrm{~Hz}$, and it could be seen from Figure 26 that Taft ground motion had relatively more high frequency energy especially around the second structural modal frequency. In this case, the chosen TFF would have more energy from higher frequency contents and the corresponding FDs would not show the right damage detection result. The above detection results' comparison under several ground motions implied that the proposed approach should be only used when the structural response was mainly contributed by the fundamental mode. For the structural response with dense mode contribution, time frequency separation should be first implemented before using the FD of TFF technique to detect damage.

\section{Conclusions}

In this paper, an extension of a data-driven approach proposed by the authors for detecting damage of shear-type 


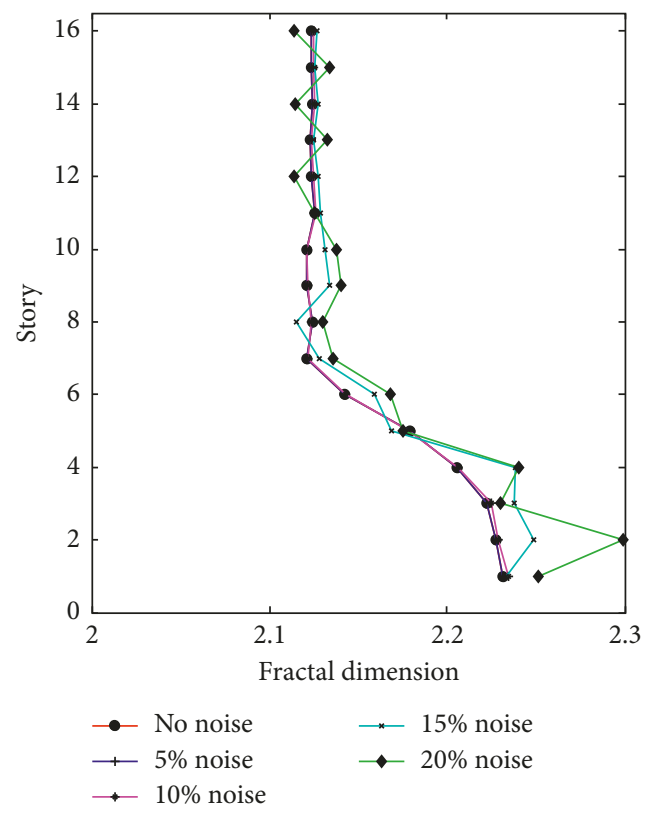

Figure 23: FDs of the TFFs of interstory displacements under different noise levels (Case 5).

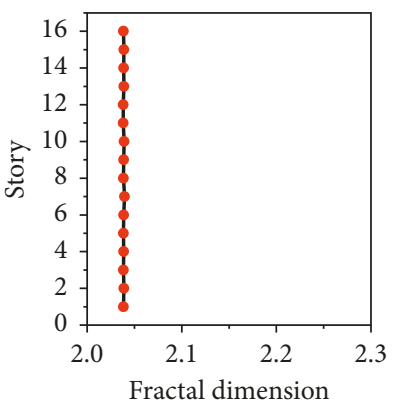

(a)

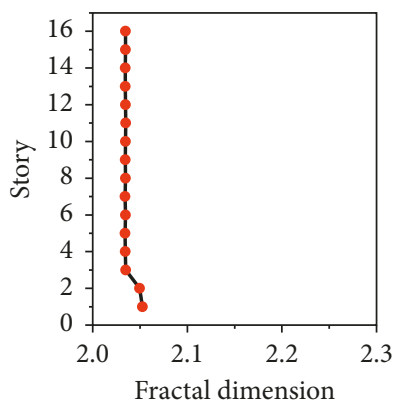

(b)

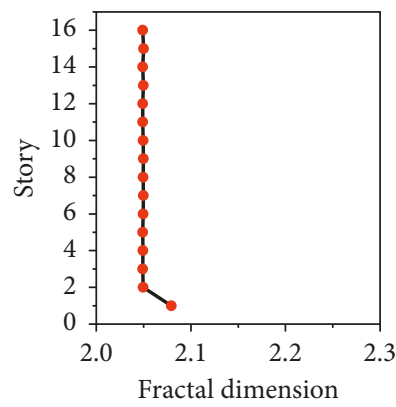

(c)

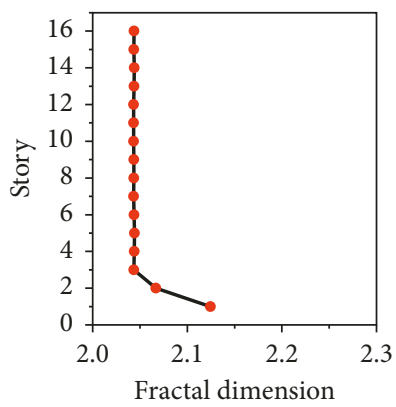

(d)

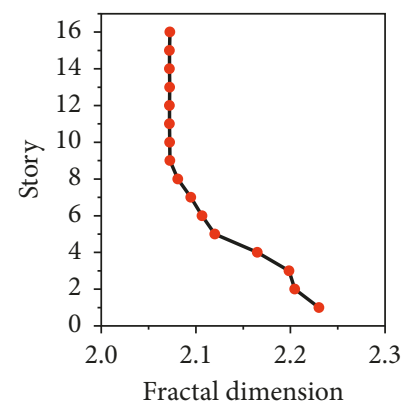

(e)

FIgURE 24: FDs of the TFFs of interstory displacements of the structure under Northridge ground motion for Cases 6-10. (a) Case 6, (b) Case 7, (c) Case 8, (d) Case 9, and (e) Case 10.

building structure is refined and further developed to detect seismic damage of MRF subjected to far-field or near-field strong ground motions. The method is one kind of vibration-based approach, which uses the measured displacements to detect damage and locate stories with plastic hinges at the ends of beams and columns. The principle is that the FD of TFF of interstory displacements with inelastic component are different from the FD of TFF of the interstory displacements that do not contain inelastic component. The numerical simulation on a 16-story MRF indicates that the method can locate the stories in which there are plastic hinges at the end of beams and columns. The damaged story location accuracy is better when the plastic hinges are at the end of columns than those at the end of 

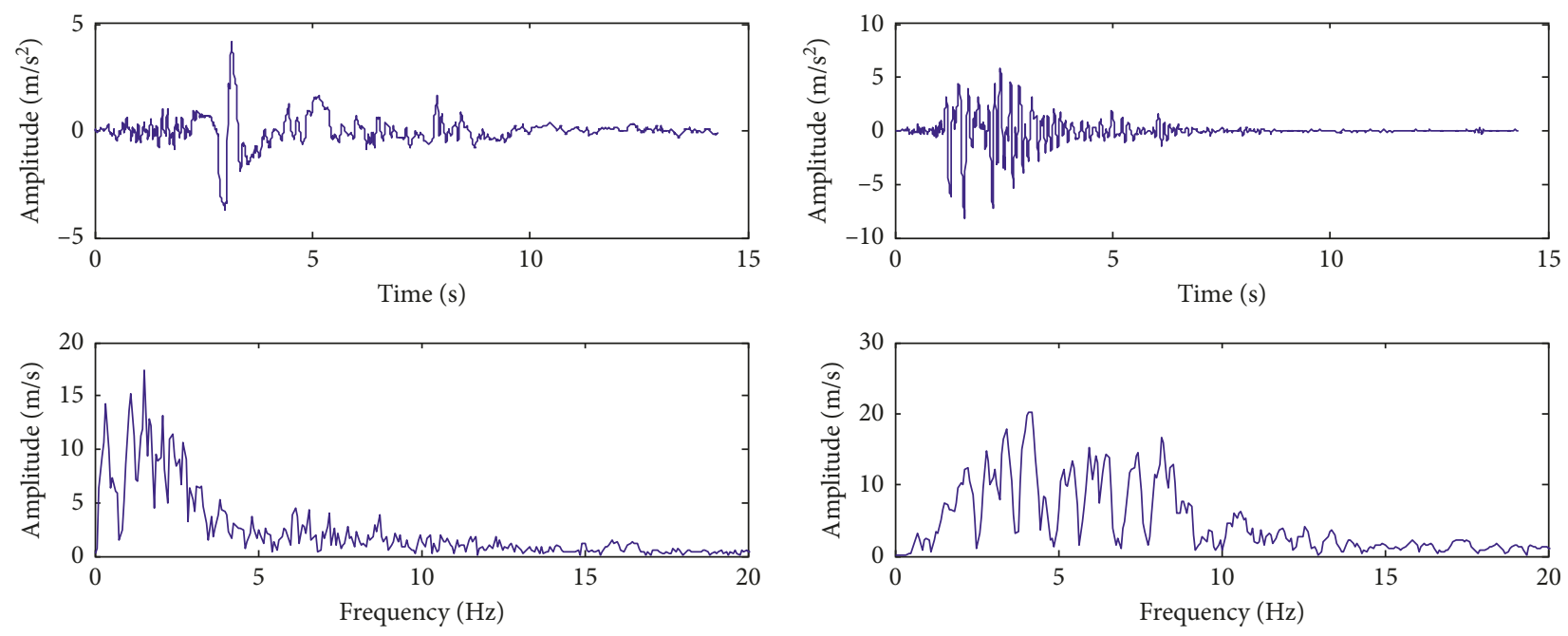

(a)

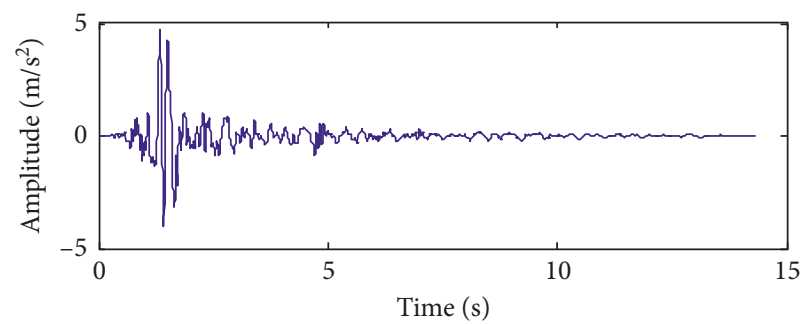

(b)
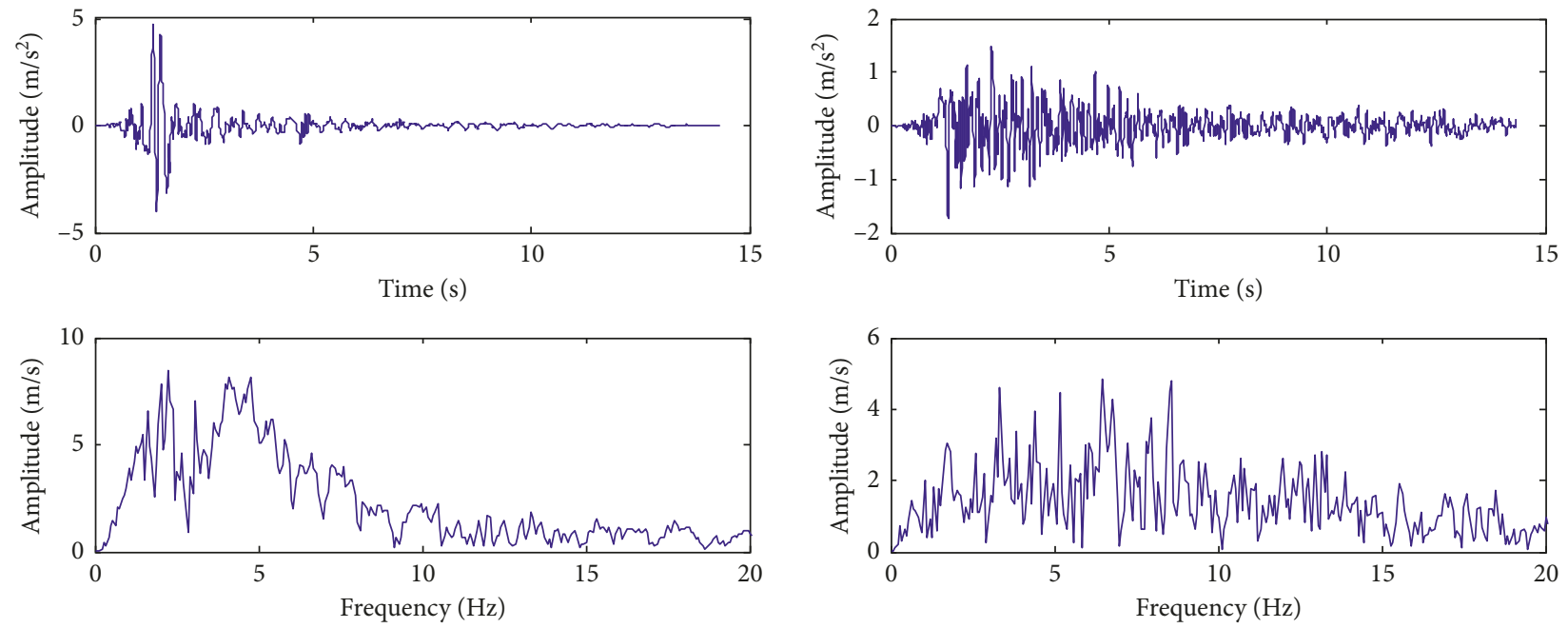

(c)

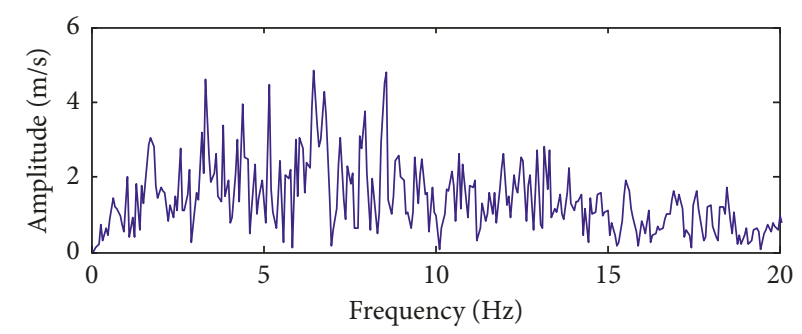

(d)

Figure 25: Time histories, and the FFT spectra of strong ground motions. (a) Chichi, (b) Kobe, (c) Parkfield, and (d) Taft.

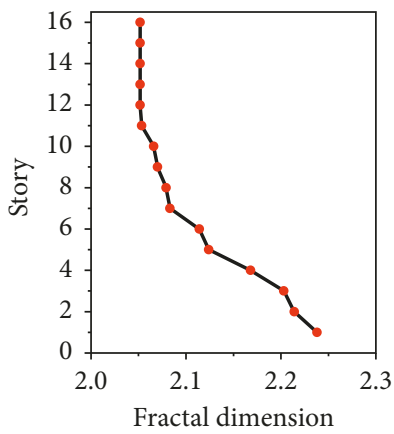

(a)

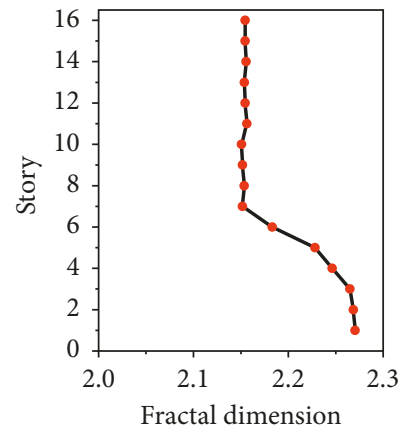

(b)

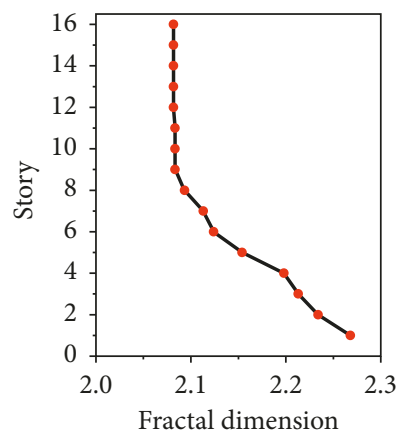

(c)

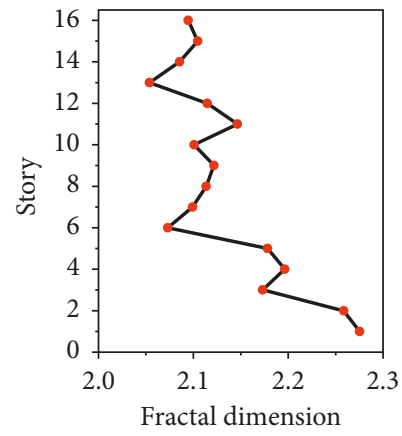

(d)

FIGURE 26: FDs of the TFFs of interstory displacements of the structure under strong ground motions when all the yielding stress of beams and columns as $205 \mathrm{MPa}$. (a) Chichi, (b) Kobe, (c) Parkfield, and (d) Taft.

beams. As the seismic damage of real MRF structure will introduce plastic hinges at the ends of beams or columns, the method may be utilized for detecting and localizing these kinds of damage. Further study will include experiment validation on a MRF in shaking table test, and testing on insitu MRF under real ground motions will also be conducted. 


\section{Data Availability}

The input ground motions were obtained from Pacific Earthquake Engineering Research (PEER) strong-motion database at https://ngawest2.berkeley.edu/ (last accessed March 2018, login required), and the structural response data used to support the results of this study are available from the corresponding author upon request.

\section{Conflicts of Interest}

The authors declare that there are no conflicts of interest regarding the publication of this paper.

\section{Acknowledgments}

This work was supported by the Science Foundation of the Institute of Engineering Mechanics, China Earthquake Administration (Grant nos. 2014B08 and 2016A03), National Natural Science Foundation of China (Grant no. 5150082083), and China Scholarship Council (Grant no. 201704190039). The first author is grateful to Professor Zhenming Wang at Kentucky Geological Survey, University of Kentucky, for his great support and guidance and help during visit.

\section{References}

[1] M. Çelebi, "Seismic monitoring of structures and new developments," in Earthquakes and Health Monitoring of Civil Structures, M. Garevski, Ed., pp. 37-84, Springer Environmental Science and Engineering, Springer, Dordrecht, Netherlands, 2013.

[2] S. Okada and N. Takai, "Classifications of structural types and damage patterns of buildings for earthquake field investigation," in Proceedings of the 12th World Conference on Earthquake Engineering, vol. 30, pp. 1-8, Auckland, New Zealand, 2000.

[3] K. Kusunoki and M. Teshigawara, "Development of real-time residual seismic capacity evaluation system-integral method and shaking table test with plain steel frame," in Proceedings of the 13th World Conference on Earthquake Engineering, Vancouver, BC, Canada, August 2004.

[4] E. Carden and P. Fanning, "Vibration based condition monitoring: a review," Structural Health Monitoring, vol. 3, no. 4, pp. 355-377, 2004.

[5] S. Liu, M. Tomizuka, and G. Ulsoy, "Strategic issues in sensors and smart structures," Structural Control and Health Monitoring, vol. 13, no. 6, pp. 946-957, 2006.

[6] J. Ou and H. Li, "Structural health monitoring in mainland China: review and future trends," Structural Health Monitoring, vol. 9, no. 3, pp. 219-231, 2010.

[7] Y. Liu and S. Nayak, "Structural health monitoring: State of the art and perspectives," JOM, vol. 64, no. 7, pp. 789-792, 2012.

[8] P. Chang, A. Flatau, and S. Liu, "Health monitoring of civil infrastructure," Structural Health Monitoring, vol. 2, no. 3, pp. 257-267, 2003.

[9] J. Kullaa, "Structural health monitoring under nonlinear environmental or operational influences," Shock and Vibration, vol. 2014, Article ID 863494, 9 pages, 2014.
[10] H. Kordestani, Y. Xiang, and X. Ye, "Output-only damage detection of steel beam using moving average filter," Shock and Vibration, vol. 2018, Article ID 2067680, 13 pages, 2018.

[11] G. Boscato, M. Pizzolato, S. Russo, and A. Tralli, "Seismic behavior of a complex historical church in L'Aquila," International Journal of Architectural Heritage, vol. 8, no. 5, pp. 718-757, 2014

[12] G. Boscato, A. D. Cin, S. Russo, and F. Sciarretta, "SHM of historic damaged churches," in Advanced Materials Research, vol. 838, pp. 2071-2078, Trans Tech Publications, Zürich, Switzerland, 2014.

[13] R. Ceravolo, G. Pistone, L. Zanotti Fragonara, S. Massetto, and G. Abbiati, "Vibration-based monitoring and diagnosis of cultural heritage: a methodological discussion in three examples," International Journal of Architectural Heritage, vol. 10, no. 4, pp. 375-395, 2016.

[14] L. Zanotti Fragonara, G. Boscato, R. Ceravolo et al., "Dynamic investigation on the Mirandola bell tower in post-earthquake scenarios," Bulletin of Earthquake Engineering, vol. 15, no. 1, pp. 313-337, 2017.

[15] C. Farrar, K. Worden, M. Todd et al., Nonlinear System Identification for Damage Detection, No. LA-14353-MS, Los Alamos National Laboratory (LANL), Los Alamos, NM, USA, 2007.

[16] W. Staszewski and A. Robertson, "Time-frequency and timescale analysis for structural health monitoring," Philosophical Transactions of the Royal Society A: Mathematical, Physical and Engineering Sciences, vol. 365, no. 1851, pp. 449-477, 2007.

[17] A. N. Robertson and B. Basu, "Wavelet analysis," in Encyclopedia of Structural Health Monitoring, C. Boller, F. Chang, and Y. Fujino, Eds., Wiley, Hoboken, NJ, USA, 2009.

[18] R. Ceravolo, "Time-frequency analysis," in Encyclopedia of Structural Health Monitoring, C. Boller, F. Chang, and Y. Fujino, Eds., Wiley, Hoboken, NJ, USA, 2009.

[19] A. Robertson, C. Farrar, and H. Sohn, "Singularity detection for structural health monitoring using holder exponents," Mechanical Systems and Signal Processing, vol. 17, no. 6, pp. 1163-1184, 2003.

[20] M. Civera, L. Zanotti Fragonara, and C. Surace, "A novel approach to damage localisation based on bispectral analysis and neural network," Smart Structures Systems, vol. 20, no. 6, pp. 669-682, 2017.

[21] K. Liew and Q. Wang, "Application of wavelet theory for crack identification in structures," Journal of Engineering Mechanics, vol. 124, no. 2, pp. 152-157, 1998.

[22] C. H. Loh and H. M. Lin, "Application of off-line and on-line identification techniques to building seismic response data," Earthquake Engineering \& Structural Dynamics, vol. 25, no. 3, pp. 269-290, 1996.

[23] C. H. Loh, C. H. Mao, S. H. Chao, and J. H. Weng, "Feature extraction and system identification of reinforced concrete structures considering degrading hysteresis," Structural Control and Health Monitoring, vol. 17, no. 7, pp. 712-729, 2010.

[24] M. Vafaei and A. Adnan, "Seismic damage detection of tall airport traffic control towers using wavelet analysis," Structure and Infrastructure Engineering, vol. 10, no. 1, pp. 106-127, 2014.

[25] A. Kumar and L. Zanotti Fragonara, "Identification of weak non-linearities in cables of cable-stayed footbridges," International Journal of Lifecycle Performance Engineering, vol. 1, no. 3, pp. 292-313, 2013. 
[26] S. Nagarajaiah and B. Basu, "Output only modal identification and structural damage detection using time frequency \& wavelet techniques," Earthquake Engineering and Engineering Vibration, vol. 8, no. 4, pp. 583-605, 2009.

[27] Y. Huang, H. Li, S. Wu, and Y. Yang, "Fractal dimension based damage identification incorporating multitask sparse Bayesian learning," Smart Materials and Structures, vol. 27, no. 7, article 075020, 2018.

[28] H. Li, Y. Huang, J. Ou, and Y. Bao, "Fractal dimension-based damage detection method for beams with a uniform crosssection," Compute-Aided Civil and Infrastructure Engineering, vol. 26, no. 3, pp. 190-206, 2011.

[29] J. M. Nichols, S. T. Trickey, M. D. Todd, and L. N. Virgin, "Structural health monitoring through chaotic interrogation," Meccanica, vol. 38, no. 2, pp. 239-250, 2003.

[30] T. K. Lin and H. Fajri, "Damage detection of structures with detrended fluctuation and detrended cross-correlation analyses," Smart Materials and Structures, vol. 26, no. 3, article 035027, 2017.

[31] H. Li, D. Tao, Y. Huang, and Y. Bao, "A data-driven approach for seismic damage detection of shear-type building structures using the fractal dimension of time-frequency features," Structural Control and Health Monitoring, vol. 20, no. 9, pp. 1191-1210, 2013.

[32] J. Carrillo and W. Avila, "Assessment of seismic damage of thin and lightly reinforced concrete walls using fractal dimension of cracking," Earthquake Engineering \& Structural Dynamics, vol. 46, no. 4, pp. 661-675, 2017.

[33] W. Y. Ma and B. S. Manjunath, "A comparison of wavelet transform features for texture image annotation," in Proceedings of International Conference on Image Processing, 1995, vol. 2, pp. 256-259, IEEE, Washington, DC, USA, October 1995.

[34] N. Sarkar and B. B. Chaudhuri, "An efficient differential boxcounting approach to compute fractal dimension of image," IEEE Transactions on Systems, Man, and Cybernetics, vol. 24, no. 1, pp. 115-120, 1994.

[35] K. Wong and R. Yang, "Inelastic dynamic response of structures using force analogy method," Journal of Engineering Mechanics, vol. 125, no. 10, pp. 1190-1199, 1999.

[36] F. McKenna, "OpenSees: a framework for earthquake engineering simulation," Computing in Science \& Engineering, vol. 13, no. 4, pp. 58-66, 2011.

[37] J. Buckheit and D. Donoho, "Wavelab and reproducible research," in Wavelets and Statistics, pp. 55-81, Springer, New York, NY, USA, 1995.

[38] C. Canus, P. Goncalves, B. Guiheneuf, and J. L. Vehel, "FracLab: a fractal analysis toolbox for signal and image processing," March 2018, http://fraclab.saclay.inria.fr/. 


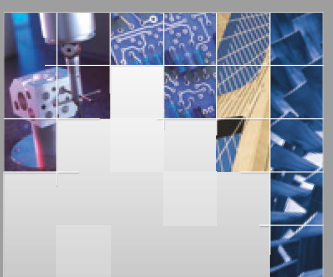

\section{Enfincering}
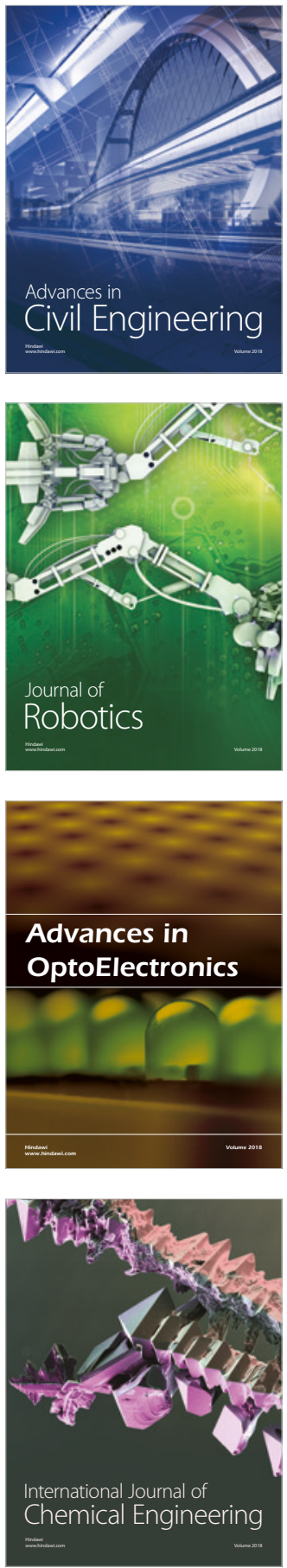

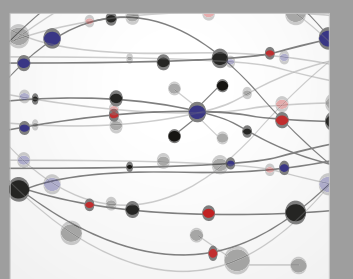

\section{Rotating \\ Machinery}

The Scientific World Journal

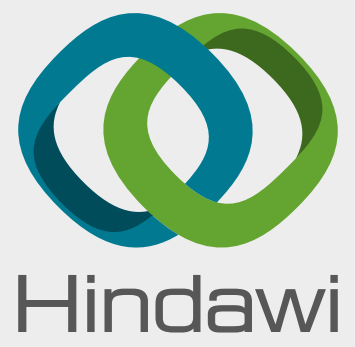

Submit your manuscripts at

www.hindawi.com
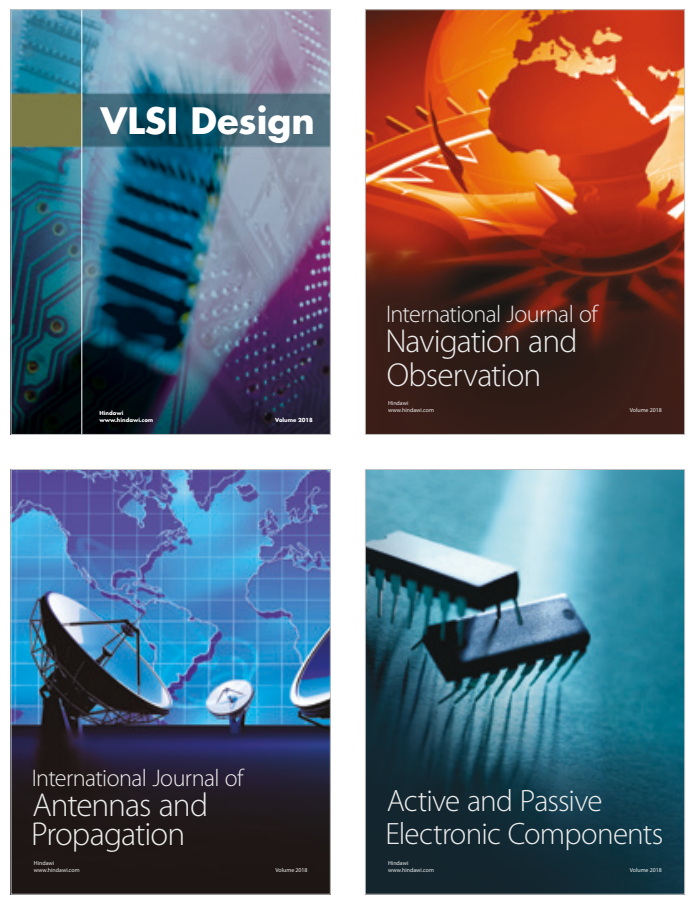
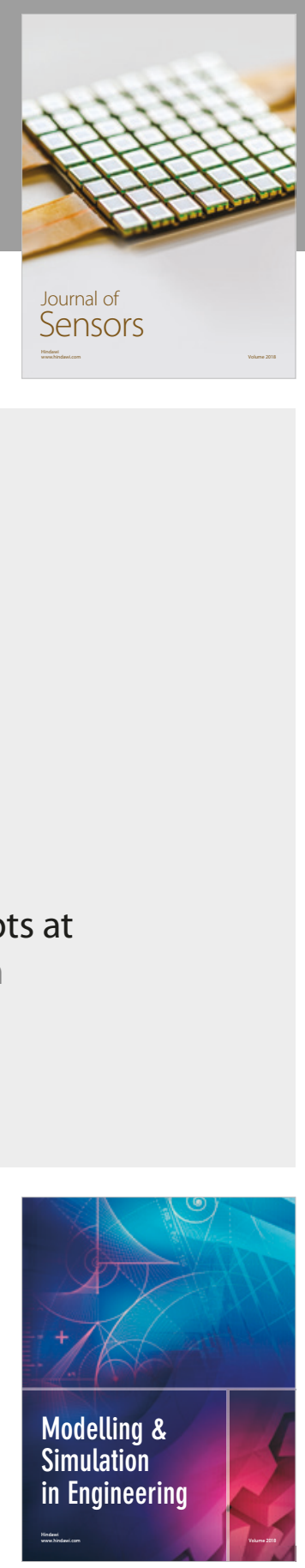

\section{Advances \\ Multimedia}
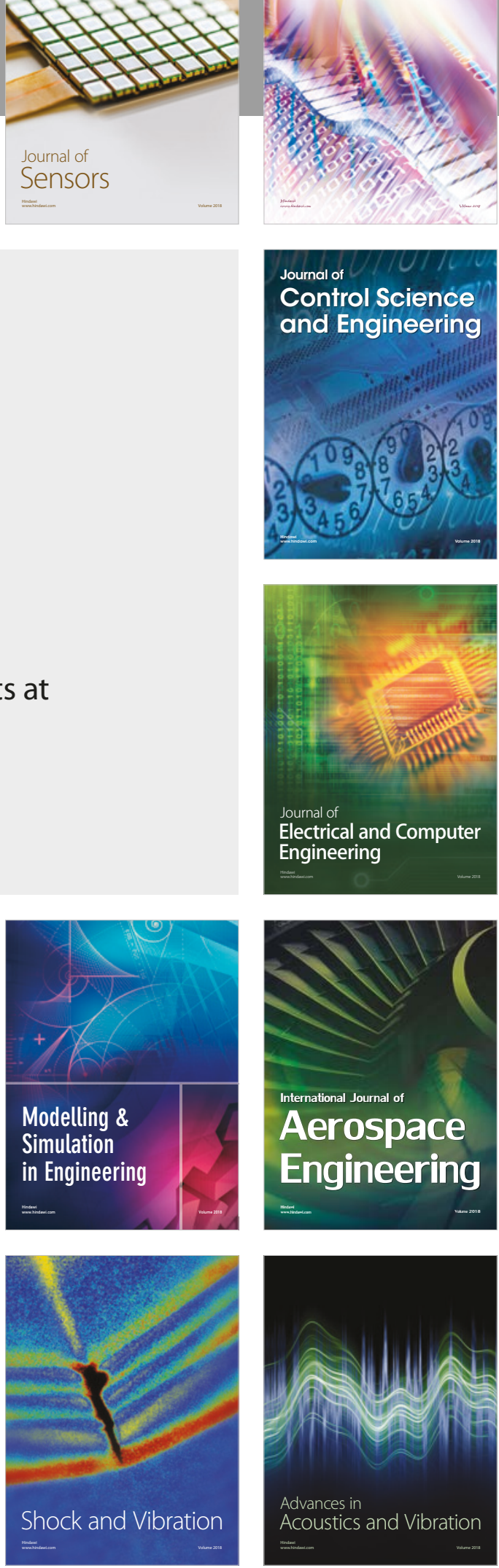